\title{
Transcriptome profiling shows gene regulation patterns in a flavonoid pathway in response to exogenous phenylalanine in Boesenbergia rotunda cell culture
}

Noor Diyana Md-Mustafa ${ }^{1,2}$, Norzulaani Khalid ${ }^{1,2}$, Huan Gao ${ }^{6}$, Zhiyu Peng ${ }^{5,6}$, Mohd Firdaus Alimin $^{4}$, Noraini Bujang ${ }^{4}$, Wong Sher Ming ${ }^{1,2}$, Yusmin Mohd-Yusuf ${ }^{1,3}$, Jennifer A Harikrishna ${ }^{1,2}$ and Rofina Yasmin Othman ${ }^{1,2^{*}}$

\begin{abstract}
Background: Panduratin A extracted from Boesenbergia rotunda is a flavonoid reported to possess a range of medicinal indications which include anti-dengue, anti-HIV, anti-cancer, antioxidant and anti-inflammatory properties. Boesenbergia rotunda is a plant from the Zingiberaceae family commonly used as a food ingredient and traditional medicine in Southeast Asia and China. Reports on the health benefits of secondary metabolites extracted from Boesenbergia rotunda over the last few years has resulted in rising demands for panduratin A. However large scale extraction has been hindered by the naturally low abundance of the compound and limited knowledge of its biosynthetic pathway.

Results: Transcriptome sequencing and digital gene expression (DGE) analysis of native and phenylalanine treated Boesenbergia rotunda cell suspension cultures were carried out to elucidate the key genes differentially expressed in the panduratin A biosynthetic pathway. Based on experiments that show increase in panduratin A production after 14 days post treatment with exogenous phenylalanine, an aromatic amino acid derived from the shikimic acid pathway, total RNA of untreated and 14 days post-phenylalanine treated cell suspension cultures were extracted and sequenced using next generation sequencing technology employing an Illumina-Solexa platform. The transcriptome data generated 101, 043 unigenes with 50, $932(50.41 \%)$ successfully annotated in the public protein databases; including 49.93\% $(50,447)$ in the non-redundant (NR) database, 34.63\% $(34,989)$ in Swiss-Prot, $24,07 \%(24,316)$ in Kyoto Encyclopedia of Genes and Genomes (KEGG) and 16.26\% $(16,426)$ in Clusters of Orthologous Groups (COG). Through DGE analysis, we found that 14, 644 unigenes were up-regulated and 14, 379 unigenes down-regulated in response to exogenous phenylalanine treatment. In the phenylpropanoid pathway leading to the proposed panduratin $\mathrm{A}$ production, 2 up-regulated phenylalanine ammonia-lyase (PAL), 3 up-regulated 4-coumaroyl:coenzyme A ligase (4CL) and 1 up-regulated chalcone synthase (CHS) were found.
\end{abstract}

Conclusions: This is the first report of Boesenbergia rotunda de novo transcriptome data that could serve as a reference for gene or enzyme functional studies in the Zingiberaceae family. Although enzymes that are directly involved in the panduratin A biosynthetic pathway were not completely elucidated, the data provides an overall picture of gene regulation patterns leading to panduratin A production.

Keywords: Boesenbergia rotunda, panduratin A, anti-dengue, RNA-seq, differentially expressed genes (DEGs) analysis, phenylpropanoid pathway

\footnotetext{
* Correspondence: yasmin@um.edu.my

${ }^{1}$ Centre for Research in Biotechnology for Agriculture (CEBAR), University of

Malaya, 50603 Kuala Lumpur, Malaysia

${ }^{2}$ Institute of Biological Sciences, Faculty of Science, University of Malaya,

50603 Kuala Lumpur, Malaysia

Full list of author information is available at the end of the article
}

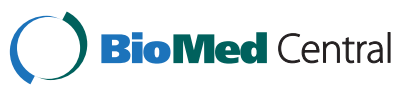

(c) 2014 Md-Mustafa et al.; licensee BioMed Central Ltd. This is an Open Access article distributed under the terms of the Creative Commons Attribution License (http://creativecommons.org/licenses/by/2.0), which permits unrestricted use, distribution, and reproduction in any medium, provided the original work is properly credited. The Creative Commons Public Domain Dedication waiver (http://creativecommons.org/publicdomain/zero/1.0/) applies to the data made available in this article, unless otherwise stated. 


\section{Background}

Boesenbergia rotunda (Linnaeus) Mansfield, Kulturpflanze is a synonym of Gastrochilus panduratum Ridley, Boesenbergia pandurata (Roxb.), Kaempferia pandurata Roxb. and Gastrochilus panduratus (Roxb.) Ridl. and is believed to have originated from the Indian, Southern China and Southeast Asia regions [1-3]. It is a traditional medicinal plant known locally in Malaysia and Indonesia as temu kunci, merkunci, dekunci or temu kecil [3], in Thailand as kra-chai [4], in China as Chinese ginger or Chinese keys, while its English name is finger root ginger.

Boesenbergia rotunda (L.) is a perennial herb belonging to the Zingiberaceae family. It is a small herbaceous plant with short, slender rhizomes [5]. The rhizomes are widely used in Southeast Asia as an edible spice or vegetable and in ethnomedicine as an ingredient for the treatment of aphthous ulcers, dry mouth, stomach discomforts, leucorrhoea, dysentery, inflammation, rheumatism and muscular pains $[3,4]$. Traditionally, their rhizomes are eaten raw to treat mouth ulcers [6] or prepared together with other medicinal plant rhizomes as a tonic for postnatal treatment to restore blood circulation and to rejuvenate the body $[1,6]$. Crushed rhizomes are used externally to release stomach gas, improve appetite, improve digestion and treat rheumatism $[1,6]$.

The major bioactive constituents in Boesenbergia rotunda are flavonoids. To date, more than 20 flavonoids have been isolated from Boesenbergia rotunda and are classified into two main groups, flavanones and chalcones. Based on their flavonoid carbon skeleton structure, compounds that can be classified as flavanones include pinocembrin, pinostrobin, alpinetin, rotundaflavone I and rotundaflavone II, while cardamonin, 4-hydroxypanduratin $\mathrm{A}$, panduratin $\mathrm{A}$, isopanduratin $\mathrm{A}$, boesenbergin $\mathrm{A}$, krachaizin $\mathrm{A}$ and krachaizin $\mathrm{B}$ are classified as chalcones [7-12]. Among isolated secondary metabolites from Boesenbergia rotunda, panduratin A has been shown to possess various medicinal properties which include antidengue, anti-cancer, anti-inflammatory, anti-HIV-1 protease, antibacterial, anti-aging, antioxidant and anti-obesity properties [13-31].

Panduratin A and 4-hydroxypanduratin A were reported to exhibit stronger biological activities compared to other secondary metabolites in Boesenbergia rotunda [17]. In a previous study, panduratin A has been shown to have anti-dengue properties through inhibition of dengue-2 virus NS3 protease which eventually leads to the termination of viral replication [13]. Dengue is a fast emerging pandemic viral disease in tropical and sub-tropical regions worldwide [32]. The World Health Organization (WHO) reported that 2.5 billion people or about $40 \%$ of the world population, are now at risk of dengue with an estimated 50 - 100 million dengue infections worldwide annually [32]. Severe dengue or formally known as Dengue Haemorrhagic
Fever has become leading cause of hospitalization and death. The WHO estimates that about 500000 people are infected with severe dengue each year with $2.5 \%$ mortality [32]. To date there are no licensed dengue treatments while the frequency of dengue outbreaks are increasing each year [33].

Despite the extensive reports on the potential use of panduratin A, the limited amounts of panduratin A that can be extracted from their natural source has resulted in unmet market demands when up-scaled quantities are required. Harvesting of mature rhizomes require almost a one year planting cycle for Boesenbergia rotunda. In addition, extraction of panduratin A from 10 kilograms of dried Boesenbergia rotunda rhizome using a solvent extraction method only yields approximately $715.2 \mathrm{mg}$ of panduratin A [21]. Although chemically synthesized panduratin A has been reported, the economics of the procedures continues to hinder large-scale production of panduratin A [34]. Alternatively the enhancement of panduratin A production through genetic manipulation of its secondary metabolic pathways is a potential strategy for panduratin A yield improvement and this would require knowledge of its biosynthetic pathway which at present remains unclear.

Panduratin A production has been shown in a published report from this laboratory to be enhanced by the addition of exogenous phenylalanine into Boesenbergia rotunda cell suspension cultures [35]. Phenylalanine is an aromatic amino acid produced from the shikimic acid pathway [36]. It provides the essential 6-carbon ring and 3-carbon side chain that is central to all phenylpropanoids. Phenylalanine is also the precursor for the production of cinnamic acid, the first phenylpropanoids in the phenylpropanoid pathway, which are eventually channelled into the production of most flavonoids in plants including panduratin A.

For elucidation of the genes that are involved in the panduratin A biosynthetic pathway, we have sequenced, and compared two sets of transcriptome profiles that were derived from phenylalanine treated and untreated (control) Boesenbergia rotunda cell suspension cultures. De novo transcriptome of Boesenbergia rotunda was done by combining both transcripts from control and treated samples to generate longer sequences. Subsequently, gene regulation patterns between the control and phenylalanine treated cell suspension cultures were analysed using DGE analysis by mapping both transcriptome profiles to the de novo transcriptome database. The focus of the research was to resolve the gene regulation patterns in the phenylpropanoid pathway that leads to panduratin A biosynthesis in Boesenbergia rotunda cell suspension cultures in response to exogenous phenylalanine. Additionally the de novo transcriptome data would also enrich the plant database and eventually serve as reference sequences for other Zingiberaceae family plant species. 


\section{Results}

Short -read de novo sequencing and assembly

RNA samples were extracted from control and phenylalanine treated Boesenbergia rotunda callus using a modified CTAB method [37]. Illumina-Solexa RNA sequencing technology was used to sequence the whole transcriptome of Boesenbergia rotunda. After stringent data filtering and quality checks, approximately 50 million high-quality clean reads were obtained from both samples with $95.13 \%$ and $96.06 \%$ Q20 bases (base quality was more than 20) for control and treated sample respectively. In total, there were 24, 473, 594 and 23, 470, 0648 clean paired-end reads generated with a total of 3,671 , 039, 100 and 3, 520, 597, 200 nucleotides from control Boesenbergia rotunda callus and phenylalanine treated callus respectively (Table 1 ).

Clean reads that were generated from the Illumina Genome analyzer were assembled into contigs, scaffolds and unigenes using open source SOAP denovo assembler program [38]. A total of 287, 451 and 273, 979 contigs with lengths ranging between $75-5680$ bp and $75-3739$ bp

Table 1 Summary of reads assembly generated by SOAPdenovo from control and phenylalanine treated Boesenbergia rotunda callus

\begin{tabular}{|c|c|c|}
\hline & Control & $\begin{array}{c}\text { Phenylalanine } \\
\text { treated }\end{array}$ \\
\hline Total number of reads & 24473594 & 23470648 \\
\hline Total nucleotides (nt) & 3671039100 & 3520597200 \\
\hline GC\% & $49.31 \%$ & $47.89 \%$ \\
\hline Q20\% & $95.13 \%$ & $96.06 \%$ \\
\hline \multicolumn{3}{|l|}{ Step-wise assembly } \\
\hline Total number of contig & 287451 & 273979 \\
\hline Average sequence size of contigs & 199 & 191 \\
\hline N50 length of contig & 236 & 221 \\
\hline Total number of scaffolds & 149648 & 147381 \\
\hline Average sequence size of scaffolds & 359 & 330 \\
\hline N50 length of scaffold & 535 & 465 \\
\hline Total number of unigenes & 78998 & 77541 \\
\hline Total nucleotides ( $\mathrm{nt}$ ) in unigenes & 44279890 & 39284596 \\
\hline Average sequence size of unigenes & 561 & 507 \\
\hline N50 length of unigenes & 703 & 610 \\
\hline \multicolumn{3}{|c|}{ Combined control and phenylalanine treated unigenes } \\
\hline Total number of all unigenes & \multicolumn{2}{|c|}{101043} \\
\hline $\begin{array}{l}\text { Average sequence size of all } \\
\text { unigenes }\end{array}$ & \multicolumn{2}{|r|}{599} \\
\hline N50 length of all unigenes & \multicolumn{2}{|r|}{804} \\
\hline Unigenes with orientation & \multicolumn{2}{|c|}{54284} \\
\hline Unigenes without orientation & \multicolumn{2}{|c|}{46759} \\
\hline
\end{tabular}

N50 size of contigs, scaffolds or unigene was calculated by ordering all sequences then adding the lengths from longest to shortest until the summed length exceeded $50 \%$ of the total length of all sequences. with N50 lengths of 236 and 221, for control and phenylalanine treated samples respectively. Contigs were then overlapped using paired-end read information to assemble into scaffolds. There were 149, 648 and 147, 381 scaffolds assembled from the control and treated samples with average scaffold sizes of 359 (control) and 330 (treated sample). Scaffolds from both samples lengths ranged from 100 to 12, $211 \mathrm{bp}$ for the control and from 100 to 5, $943 \mathrm{bp}$ for the treated sample.

Subsequently, scaffolds were overlapped and paired-end reads were used to fill the scaffold gaps to obtain unigenes. For the control sample, there were 78, 998 unigenes assembled with lengths ranging from 200 to 12, 209 bp and a N50 length of $703 \mathrm{bp}$; while for the treated sample, there were 77,541 unigenes assembled with lengths ranging from 200 to 5, 944 bp with a N50 length of $610 \mathrm{bp}$. Finally, longer sequences denoted as All Unigenes, were assembled by overlapping both control and phenylalanine treated unigenes followed by removing redundant sequences using TGICL software. There were in total approximately 101, 043 All Unigenes assembled with lengths ranging from 200 to 12 , 209 bp. The N50 lengths of All unigenes were 804 bp. Additional file 1 shows the length distribution, while Additional file 2 shows gap distribution of the control unigene, phenylalanine treated unigene and all unigenes respectively.

In order to determine the unigenes' sequence orientation, all unigenes were aligned using BlastX alignment ( $e$ value $<1.00 \mathrm{E}-05$ ) against four protein databases with the priority order of GenBank non-redundant (NR), Swiss-Prot, Kyoto Encyclopedia of Genes and Genomes (KEGG) and Clusters of Orthologous Groups (COG). Remaining unaligned unigenes were analyzed using ESTscan software [39] to predict the coding regions and to decide on sequence direction. The best-aligned results showed that 54, 284 unigenes are oriented while 46, 759 are non-oriented unigenes (Table 1).

\section{Functional annotation and gene ontology classification}

Functional annotation gave information on protein function annotation, pathway annotation, COG annotation and Gene Ontology (GO) annotation. Unigenes with sequence orientation was aligned against public protein databases such as NR, Swiss-Prot, KEGG and COG using BlastX homology search ( $e$ value $<1.00 \mathrm{E}-05)$, which is based on sequence similarities to the published protein databases. There were in total 50, 932 (50.41\%) unigenes successfully annotated (Table 2). Most of the unigenes were annotated using the NR database (49.93\%) followed by Swiss-Prot (34.63\%), KEGG (24.07\%) and COG (16.26\%). The remainder had no matches.

Clusters Orthologous Groups of proteins (COG) database contain orthologous proteins that were classified under several categories. Unigenes were aligned to COG database to predict and classify their possible function. Figure 1 shows 
Table 2 Functional annotation of Boesenbergia rotunda transcriptome data in four public protein databases

\begin{tabular}{lcc}
\hline Public protein database & No. of unigene hits & Percentage \\
\hline NR & 50447 & 49.93 \\
Swiss-Prot & 34989 & 34.63 \\
KEGG & 24316 & 24.07 \\
COG & 16426 & 16.26 \\
Total & 50932 & 50.41 \\
\hline
\end{tabular}

The databases include Non-redundant (NR), Swiss-Prot, Kyoto Encyclopedia of Genes and Genomes (KEGG) and Cluster Orthologous Group (COG).

the distributions of 16, 526 unigenes assigned into 25 orthologous clusters in COG. Some unigenes may be assigned into several clusters in COG categories; while some unigenes were assigned to the same cluster but with different protein orthologous similarity. In total, there were 34, 434 unigenes that were assigned to COG database (Additional file 3). The majority of the unigenes were distributed in general function prediction $(4,851)$ followed by transcription $(3,691)$; and replication, recombination and repair $(3,053)$. A total of 1,863 functionally unknown unigenes were identified. Whereas, 753 unigenes were assigned to secondary metabolites biosynthesis, transport and catabolism and 395 as defense mechanism unigenes.

Unigene with NR annotation was further annotated and classified under Gene Ontology (GO). GO is an international standardized gene functional classification system. It has three ontologies which include molecular function, cellular component and biological properties. The basic unit of GO $0 \mathrm{~s}$ GO-term and every GO-term belongs to a type of ontology. Figure 2 shows the distribution of unigenes assigned in Gene Ontology. In total, there were 33,984 unigenes were mapped to GO with 7, 451 unigenes assigned to molecular function, 16,493 unigenes assigned to cellular components and 10, 040 unigenes assigned to biological process (Additional file 4). One unigene may be assign into several different GO-terms.

\section{Differentially expressed unigenes analysis}

Unigene expression was calculated using reads per $\mathrm{kb}$ per million reads (RPKM) method. Through this calculation, up-regulated and down-regulated of both control and phenylalanine treated transcripts were determined. However, in order to distinguish between significant and non-significant differentially expressed genes (DEGs), additional equations were employed. Significant differentially expressed genes (DEGs) were determined using Poisson distribution equation, with set the threshold of False Discovery Rate (FDR) lower or equal to 0.001 and the absolute value of $\log 2$ ratio lower or equal to 1 (Figure 3 ). In total, there were 14, 644 and 14, 379 unigenes showing significant differential expression respectively (Table 3 ).

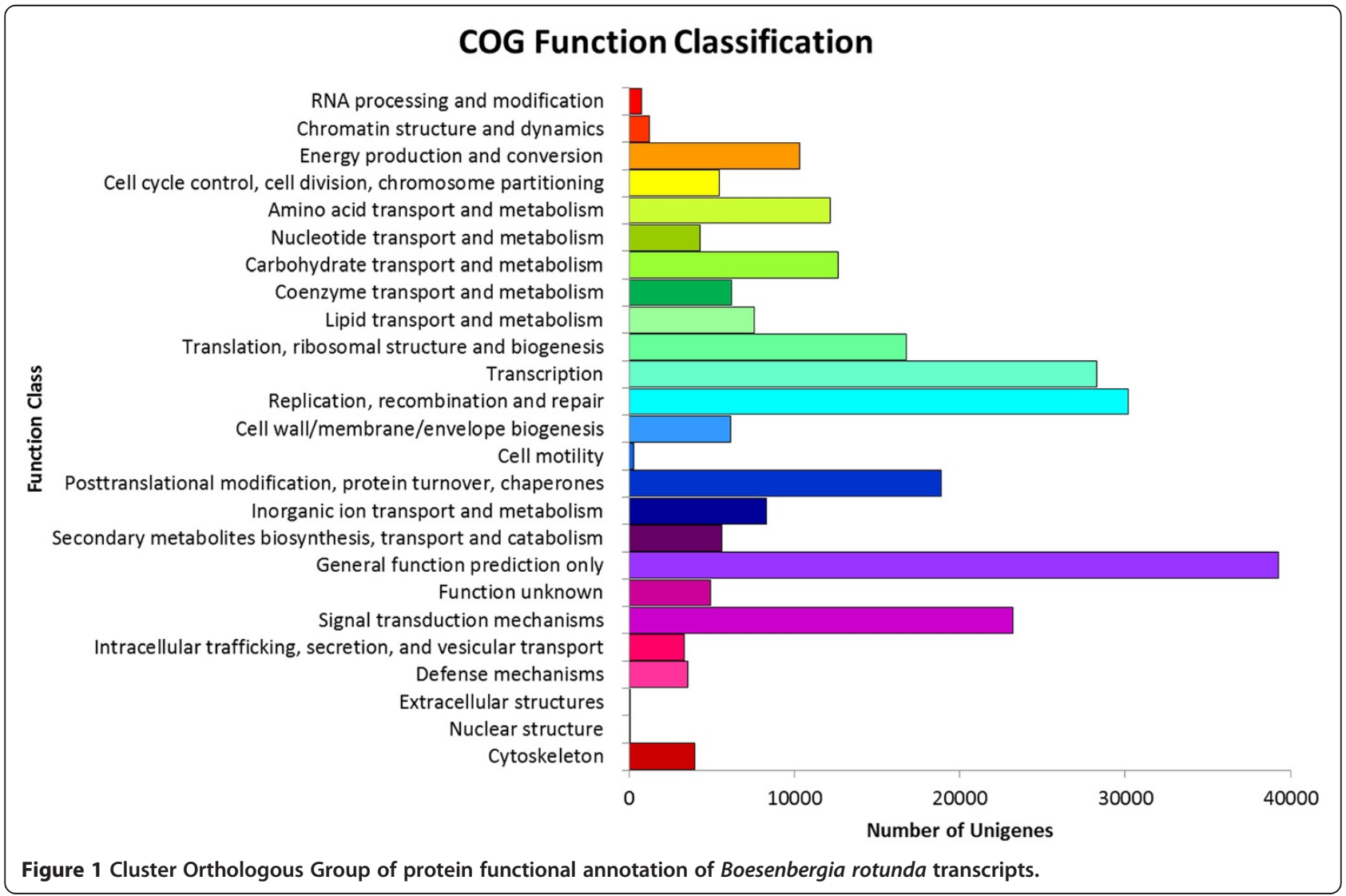




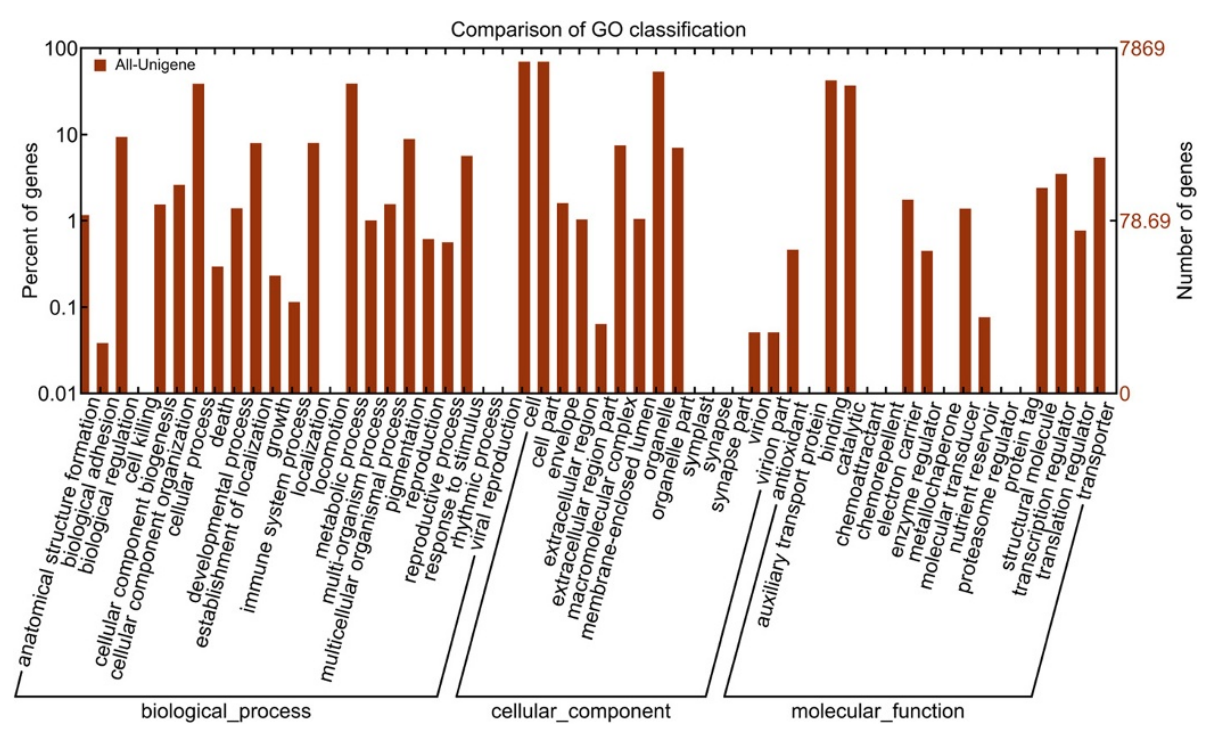

Figure 2 Histogram presentation of unigene distributions in Gene Ontology (GO) functional classification. Unigenes were further classified into sub-groups in biological process, cellular component and molecular function.

Transcription factors and transcription regulators analysis Transcription factors (TFs) and transcription regulators (TRs) play essential roles in regulating differentially expressed genes in both a spatial and temporal manner. In total, 139 transcription factors that are found in
Boesenbergia rotunda can be further classified under 35 transcription factor families (Table 4). Based on the iTAK rice transcription factor database, 21 rice TFs were not found in Boesenbergia rotunda. The most abundant TFs found in Boesenbergia rotunda was C3H (17),

\section{Expression Level TC vs TT}

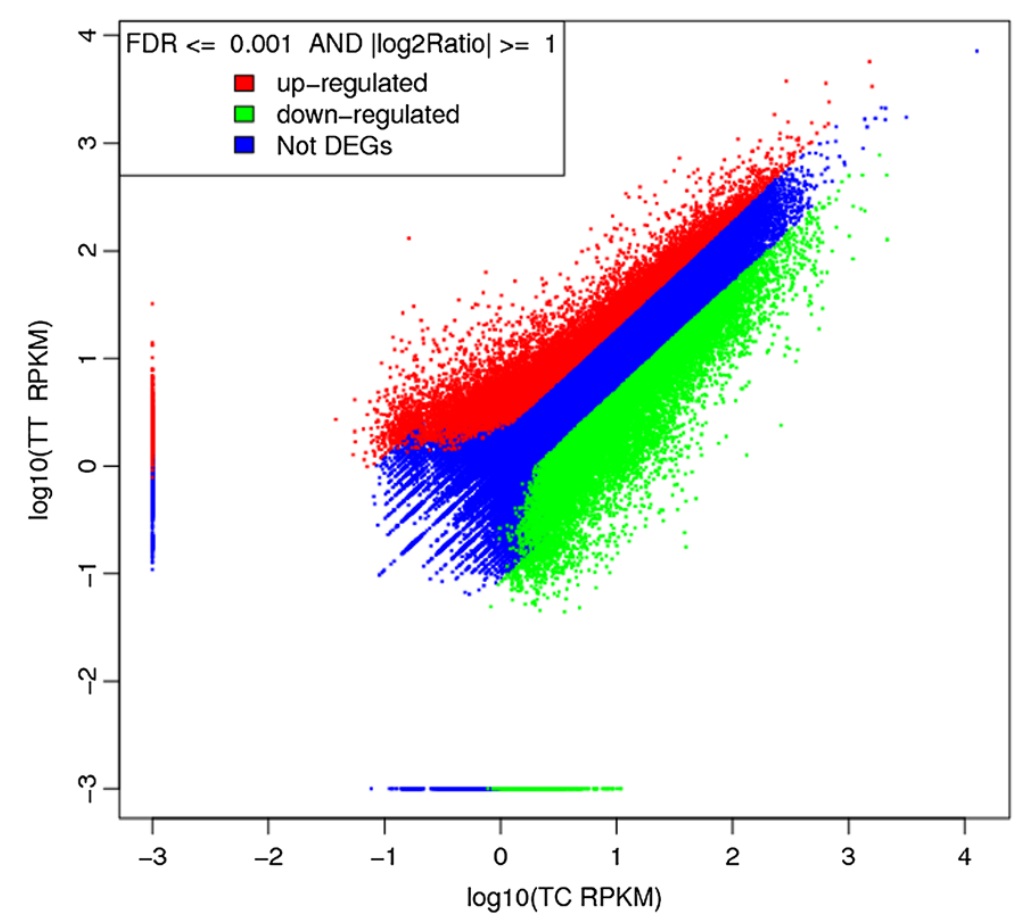

Figure 3 Expression levels of differentially expressed genes in control (TC) and phenylalanine treated (TT) samples. Up-regulated and down-regulated genes are denoted by red and green spots respectively, while not differentially expressed genes are denoted as blue spots. 
Table 3 Summary of differentially expressed genes (DEGs) expression levels in Boesenbergia rotunda transcriptome data

\begin{tabular}{lccc}
\hline & Total & Up & Down \\
\hline Total DEGs & 100869 & 47451 & 53418 \\
Significant DEGs & 29023 & 14644 & 14379 \\
$\quad$-with annotation & 16018 & 6104 & 9914 \\
$\quad$-without annotation & 13005 & 8540 & 4465 \\
\hline
\end{tabular}

followed by MYB (16), NAC (13), WRKY (9), bZIP (8) and AP2-EREBP (7). In response to phenylalanine treatment, eight TFs were up-regulated while twenty six upTFs were down-regulated. Up-regulated TFs includes MYB, NAC, WRKY, bZIP, AP2-EREBP, G2-like, GRAS and $\mathrm{C} 2 \mathrm{C} 2-\mathrm{CO}$-like transcription factor.

Subsequently, there were 46 transcription regulators which are classified under 15 families found in Boesenbergia rotunda (Table 5). The most abundant TRs found in Boesenbergia rotunda was orphan (9), followed by AUX/IAA (8) and SET (5). There were in total only 4 TRs that were up-regulated and 9 down-regulated in response to phenylalanine. Three up-regulated TRs were orphan, AUX/IAA and SET.

\section{Pathway analysis}

Pathway-based analysis provides information and further understanding on how Boesenbergia rotunda regulate their biological functions and synthesizes secondary metabolites in response to phenylalanine at the molecular level. Usually, unigenes in the same pathways cooperate with each other to exercise their biological functions. In total, there were 24,316 unigenes that mapped to the KEGG plant database using BlastX homology search. These unigenes were classified under 166 KEGG pathways in five main categories in KEGG which includes Metabolism, Genetic Information Processing, Environmental Information Processing, Cellular Processes and Organismal Systems (Table 6). A single EC number may contain one or multiple unigenes. However, only 7,931 unigenes that were differentially expressed genes (DEGs), significantly up- or down-regulated, were mapped in the KEGG pathways. The total distribution of DEGs is represented in Figure 4. Out of 116 pathways, 16 pathways were significantly enriched with DEGs (Q value $\leq 0.05$ ) (Table 7). Figure 5 shows the comparison between all unigenes and DEGs that mapped in DEG significantly enriched pathways.

The most abundant DEGs were classified in the Metabolism category with 4,754 unigenes (Table 6), followed by Genetic Information Processing (2, 069 unigenes), Organismal Systems (711 unigenes), Cellular Processes (452 unigenes) and Environmental Information Processing (210 unigenes). There were ten sub-categories found under the
Metabolism category (Table 6). In the Metabolism category, most of the DEGs were found in the carbohydrate metabolism sub-category (38.68\%), followed by metabolism of terpenoid and polyketides (37.78\%), metabolism of other amino acid (36.66\%), energy metabolism (35.57\%) and biosynthesis of other secondary metabolites (35.26\%). Unigenes that were annotated in the Metabolism category were involved in functions related to catalysis of metabolism processes or generation of energy for primary and secondary metabolite production.

Under the carbohydrate metabolism sub-category, there were six pathways that had a calculated $Q$ value $\leq$ 0.05 (Table 7). The pathway in this sub-category with the smallest $Q$ value was the citrate cycle pathway with 102 DEGs, followed by galactose metabolism (73 DEGs), glycolysis/gluconeogenesis (155 DEGs), amino sugar and nueleotide sugar metabolism (151 DEGs), pyruvate metabolism (134 DEGs) and glyoxylate and dicarboxylate metabolism (43 DEGs). Subsequently, for the energy metabolism sub-category, there was only one pathway identified which was for nitrogen metabolism with 75 DEGs. There were three pathways with $\mathrm{Q}$ value lower than 0.05 in the amino acid metabolism sub-category, which included phenylalanine metabolism (92 DEGs), alanine, aspartate and glutamate metabolism (80 DEGs) and valine, leucine and isoleucine biosynthesis (45 DEGs). Two secondary metabolite pathways with $Q$ values lower than 0.05 were identified as terpenoid backbone biosynthesis (75 DEGs) and phenylpropanoid biosynthesis (163 DEGs). Based on the histogram in Figure 6, there were 68 unigenes up-regulated and 95 unigenes down-regulated. The highest number of up-regulated unigenes was peroxidase with 40 unigenes, while the highest down-regulated unigene was beta-glucosidase with 17 unigenes.

The Genetic Information Processing category consists of four sub-categories which include transcription (270 DEGs), translation (184 DEGs), folding, sorting and degradation (729 DEGs) and replication and repair (275 DEGs) (Table 6). Unigenes in this category mainly function in processing the correct transcription and translation processes. Aminoacyl-tRNA biosynthesis (96 DEGs) and protein processing in endoplasmic reticulum (241 DEGs) pathways in this category were shown to have Q value lower than 0.05 (Table 7).

Environmental Information Processing category consists of two subcategories which includes membrane transport (116 DEGs) and signal transduction (94 DEGs) (Table 6). However, only ABC transporter pathway (116 DEGs) under membrane transport was categorised with a $Q$ value lower than 0.05 (Table 7). In plants, there is only one sub-category in the Cellular Processes category. Transport and catabolism sub-category consists of 452 DEGs (Table 6) with 208 DEGs in endocytosis pathway showing Q values lower than 0.05 (Table 7). Finally, 
Table 4 Transcription factors identified in Boesenbergia rotunda based on transcription factors in the rice database using iTAK software

\begin{tabular}{|c|c|c|c|c|c|c|}
\hline & $\begin{array}{l}\text { Transcription factor } \\
\text { (Boesenbergia rotunda) }\end{array}$ & Number of genes & Up-regulated & Down-regulated & $\begin{array}{c}\text { Transcription factor } \\
\text { (Oryza sativa) }\end{array}$ & Number of genes \\
\hline 1 & $\mathrm{C} 3 \mathrm{H}$ & 17 & 0 & 6 & $\mathrm{C} 3 \mathrm{H}$ & 70 \\
\hline 2 & MYB & 16 & 1 & 4 & MYB & 184 \\
\hline 3 & NAC & 13 & 1 & 5 & NAC & 143 \\
\hline 4 & WRKY & 9 & 1 & 2 & WRKY & 98 \\
\hline 5 & bZIP & 8 & 1 & 1 & bZIP & 91 \\
\hline 6 & AP2-EREBP & 7 & 1 & 2 & AP2-EREBP & 164 \\
\hline 7 & $\mathrm{C} 2 \mathrm{H}_{2}$ & 5 & 0 & 0 & $\mathrm{C} 2 \mathrm{H}_{2}$ & 123 \\
\hline 8 & G2-like & 5 & 1 & 1 & G2-like & 45 \\
\hline 9 & $\mathrm{HB}$ & 5 & 0 & 1 & $\mathrm{HB}$ & 94 \\
\hline 10 & TUB & 5 & 0 & 0 & TUB & 15 \\
\hline 11 & $\mathrm{bHLH}$ & 4 & 0 & 0 & bHLH & 135 \\
\hline 12 & GRAS & 4 & 1 & 0 & GRAS & 60 \\
\hline 13 & Tify & 4 & 0 & 1 & Tify & 17 \\
\hline 14 & FAR1 & 3 & 0 & 0 & FAR1 & 8 \\
\hline 15 & $\mathrm{LOB}$ & 3 & 0 & 0 & LOB & 36 \\
\hline 16 & MADS & 3 & 0 & 0 & MADS & 69 \\
\hline 17 & PBF-2-like & 3 & 0 & 0 & PBF-2-like & 2 \\
\hline 18 & ABI3VP1 & 2 & 0 & 0 & AB|3VP1 & 55 \\
\hline 19 & Alfin-like & 2 & 0 & 0 & Alfin-like & 9 \\
\hline 20 & $\mathrm{BBR} / \mathrm{BPC}$ & 2 & 0 & 0 & $\mathrm{BBR} / \mathrm{BPC}$ & 4 \\
\hline 21 & $\mathrm{BSD}$ & 2 & 0 & 0 & BSD & 10 \\
\hline 22 & C2C2-GATA & 2 & 0 & 0 & C2C2-GATA & 25 \\
\hline 23 & SRS & 2 & 0 & 0 & SRS & 5 \\
\hline 24 & Trihelix & 2 & 0 & 0 & Trihelix & 26 \\
\hline 25 & ARF & 1 & 0 & 1 & ARF & 27 \\
\hline 26 & BES1 & 1 & 0 & 0 & BES1 & 6 \\
\hline 27 & C2C2-CO-like & 1 & 1 & 0 & C2C2-CO-like & 8 \\
\hline 28 & C2C2-YABBY & 1 & 0 & 1 & C2C2-YABBY & 8 \\
\hline 29 & CCAAT & 1 & 0 & 0 & CCAAT & 51 \\
\hline 30 & EIL & 1 & 0 & 0 & ElL & 9 \\
\hline 31 & GeBP & 1 & 0 & 0 & GeBP & 13 \\
\hline 32 & GRF & 1 & 0 & 0 & GRF & 12 \\
\hline 33 & mTERF & 1 & 0 & 1 & mTERF & 34 \\
\hline 34 & OFP & 1 & 0 & 0 & OFP & 31 \\
\hline 35 & $\mathrm{zf}-\mathrm{HD}$ & 1 & 0 & 0 & zf-HD & 14 \\
\hline 36 & ARR-B & 0 & 0 & 0 & ARR-B & 9 \\
\hline 37 & C2C2-Dof & 0 & 0 & 0 & C2C2-Dof & 30 \\
\hline 38 & CAMTA & 0 & 0 & 0 & CAMTA & 6 \\
\hline 39 & CPP & 0 & 0 & 0 & CPP & 11 \\
\hline 40 & CSD & 0 & 0 & 0 & CSD & 2 \\
\hline 41 & $\mathrm{DB}$ & 0 & 0 & 0 & DBP & 3 \\
\hline 42 & E2F-DP & 0 & 0 & 0 & E2F-DP & 8 \\
\hline
\end{tabular}


Table 4 Transcription factors identified in Boesenbergia rotunda based on transcription factors in the rice database using iTAK software (Continued)

\begin{tabular}{|c|c|c|c|c|c|c|}
\hline 43 & $\mathrm{FHA}$ & 0 & 0 & 0 & $\mathrm{FHA}$ & 18 \\
\hline 44 & HRT & 0 & 0 & 0 & HRT & 1 \\
\hline 45 & HSF & 0 & 0 & 0 & HSF & 25 \\
\hline 46 & LFY & 0 & 0 & 0 & LFY & 2 \\
\hline 47 & LIM & 0 & 0 & 0 & LIM & 6 \\
\hline 48 & PLATZ & 0 & 0 & 0 & PLATZ & 15 \\
\hline 49 & RWP-RK & 0 & 0 & 0 & RWP-RK & 13 \\
\hline 50 & S1Fa-like & 0 & 0 & 0 & S1Fa-like & 2 \\
\hline 51 & SBP & 0 & 0 & 0 & SBP & 19 \\
\hline 52 & Sigma70-like & 0 & 0 & 0 & Sigma70-like & 6 \\
\hline 53 & $\mathrm{TAZ}$ & 0 & 0 & 0 & TAZ & 6 \\
\hline 54 & $\mathrm{TCP}$ & 0 & 0 & 0 & TCP & 21 \\
\hline 55 & ULT & 0 & 0 & 0 & ULT & 2 \\
\hline 56 & VOZ & 0 & 0 & 0 & VOZ & 2 \\
\hline Total & 139 & 8 & 26 & & 1908 & \\
\hline
\end{tabular}

Table 5 Transcription regulators identified in Boesenbergia rotunda based on transcription regulators in the rice database using iTAK software

\begin{tabular}{|c|c|c|c|c|c|c|}
\hline & $\begin{array}{l}\text { Transcriptional regulator } \\
\text { (Boesenbergia rotunda) }\end{array}$ & $\begin{array}{l}\text { Number } \\
\text { of genes }\end{array}$ & Up-regulated & Down-regulated & $\begin{array}{l}\text { Transcription regulator } \\
\text { (Oryza sativa) }\end{array}$ & Number of genes \\
\hline 1 & Orphans & 9 & 2 & 3 & Orphans & 79 \\
\hline 2 & AUX/IAA & 8 & 1 & 1 & AUX/IAA & 32 \\
\hline 3 & SET & 5 & 1 & 0 & SET & 41 \\
\hline 4 & SNF2 & 4 & 0 & 2 & SNF2 & 39 \\
\hline 5 & TRAF & 4 & 0 & 1 & TRAF & 59 \\
\hline 6 & $\mathrm{RB}$ & 3 & 0 & 0 & $\mathrm{RB}$ & 2 \\
\hline 7 & SWI/SNF-BAF60b & 3 & 0 & 0 & SWI/SNF-BAF60b & 11 \\
\hline 8 & MED6 & 2 & 0 & 0 & MED6 & 1 \\
\hline 9 & PHD & 2 & 0 & 1 & PHD & 39 \\
\hline 10 & GNAT & 1 & 0 & 0 & GNAT & 35 \\
\hline 11 & HMG & 1 & 0 & 0 & HMG & 9 \\
\hline 12 & Jumonji & 1 & 0 & 0 & Jumonji & 14 \\
\hline 13 & Rcd1-like & 1 & 0 & 0 & Rcd1-like & 5 \\
\hline 14 & $\mathrm{SOH} 1$ & 1 & 0 & 0 & $\mathrm{SOH} 1$ & 2 \\
\hline 15 & SWI/SNF-SWI3 & 1 & 0 & 1 & SWI/SNF-SWI3 & 4 \\
\hline 16 & ARID & 0 & 0 & 0 & ARID & 6 \\
\hline 17 & Coactivator p15 & 0 & 0 & 0 & Coactivator p15 & 3 \\
\hline 18 & DDT & 0 & 0 & 0 & DDT & 7 \\
\hline 19 & IWS1 & 0 & 0 & 0 & IWS1 & 17 \\
\hline 20 & LUG & 0 & 0 & 0 & LUG & 6 \\
\hline 21 & MBF1 & 0 & 0 & 0 & MBF1 & 2 \\
\hline 22 & MED7 & 0 & 0 & 0 & MED7 & 1 \\
\hline 23 & Pseudo ARR-B & 0 & 0 & 0 & Pseudo ARR-B & 5 \\
\hline Total & 46 & 4 & 9 & & 419 & \\
\hline
\end{tabular}


Table 6 Distributions of all unigenes and differentially expressed genes (DEGs) in KEGG database classification

\begin{tabular}{|c|c|c|c|}
\hline Category & Sub-category & $\begin{array}{l}\text { All genes with pathway } \\
\text { annotation }\end{array}$ & $\begin{array}{c}\text { DEGs with pathway } \\
\text { annotation }\end{array}$ \\
\hline \multirow[t]{11}{*}{ Metabolism } & Amino Acid Metabolism & 2139 & 736 \\
\hline & Biosynthesis of Other Secondary Metabolites & 1092 & 385 \\
\hline & Carbohydrate Metabolism & 3353 & 1297 \\
\hline & Energy Metabolism & 937 & 352 \\
\hline & Glycan Biosynthesis and Metabolism & 278 & 86 \\
\hline & Lipid Metabolism & 1445 & 514 \\
\hline & Metabolism of Cofactors and Vitamins & 503 & 143 \\
\hline & Metabolism of Other Amino Acids & 581 & 213 \\
\hline & Metabolism of Terpenoid and Polyketides & 622 & 235 \\
\hline & Nucleotide Metabolism & 2290 & 721 \\
\hline & Total & 13240 & 4682 \\
\hline \multirow[t]{4}{*}{ Genetic Information Processing } & Folding, Sorting and Degradation & 2,062 & 729 \\
\hline & Replication and Repair & 923 & 275 \\
\hline & Translation & 3588 & 1137 \\
\hline & Total & 6,573 & 2,141 \\
\hline \multirow[t]{3}{*}{ Environmental Information Processing } & Membrane Transport & 224 & 116 \\
\hline & Signal Transduction & 288 & 94 \\
\hline & Total & 512 & 210 \\
\hline \multirow[t]{2}{*}{ Cellular Processes } & Transport and Catabolism & 1251 & 452 \\
\hline & Total & 1251 & 452 \\
\hline \multirow[t]{3}{*}{ Organismal Systems } & Environmental Adaptation & 2122 & 675 \\
\hline & Immune System & 140 & 36 \\
\hline & Total & 2262 & 711 \\
\hline Total Unigenes & & 24316 & 7931 \\
\hline
\end{tabular}

There are five major categories which include Metabolism, Genetic Information Processing, Environmental Information Processing, Cellular Processes and Organismal Systems.

environmental adaptation (675 DEGs) and immune systems (36 DEGs) were classified under the Organismal Systems category (Table 6). None of the pathways in this category had $\mathrm{Q}$ values lower than 0.05 . Table 7 also shows gene regulation patterns in the selected KEGG pathways. There are more down-regulated unigenes than up-regulated unigenes in all the pathways with the exception of the phenylalanine metabolism pathway which had more unigenes being up-regulated (Table 7).

\section{Representation of genes regulation in phenylpropanoid pathway and flavonoid pathway}

In the transcriptome data, we found that 411 unique unigenes were mapped to the phenylpropanoid pathway while 211 unigenes were mapped to the flavonoid pathway. In the phenylpropanoid pathway, 68 unigenes were up-regulated while 95 unigenes were down-regulated. Whereas in the flavonoid pathway, 11 unigenes were upregulated and 42 unigenes were down-regulated. One unigene may map to more than one enzyme in the pathway (Tables 8 and 9). Tables 8 and 9 shows the unigenes that might be involved in panduratin A biosynthesis and the number of up- and down-regulated unigenes with their respective gene regulation patterns (Figure 6). Additional files 5 and 6 show the gene regulation patterns in phenylpropanoid and flavonoid pathway, respectively. The most abundant unigenes that were mapped to the phenylpropanoid pathway was peroxidases (EC: 1.11 .1 .7 ) with a total of 90 unigenes. There were 40 unigenes that showed up-regulation while only 8 unigenes were down-regulated (Table 8).

Panduratin $\mathrm{A}$ is a chalcone derivative that is proposed to be derived from the flavonoid pathway (Figure 7). Phenylalanine is an aromatic amino acid that is produced in the shikimic acid pathway [36] and enters the phenylpropanoid pathway as an initial substrate to produce all phenylpropanoids including flavonoids (Additional file 5). It provides the essential 6-carbon ring and 3-carbon side chain that is central to all phenylpropanoids and subsequently enters the flavonoid pathway 


\section{DEGs genes with pathway annotation (7931 unigenes)}

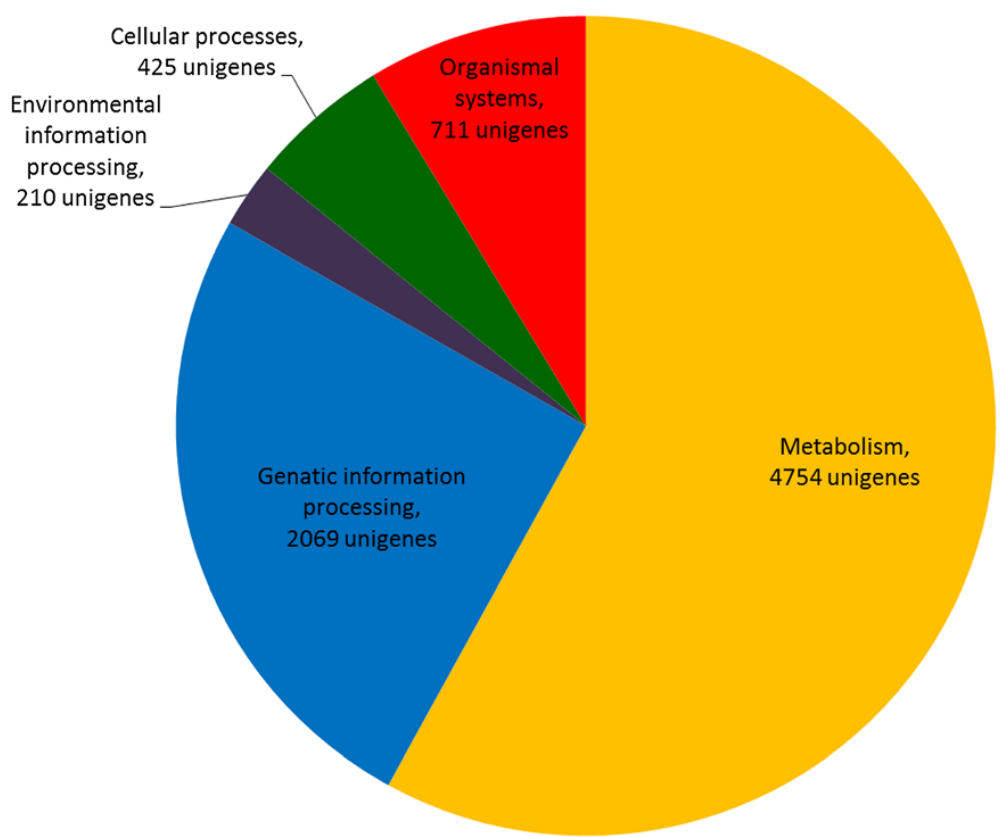

Figure 4 Distribution chart of differentially expressed genes (DEGs) in KEGG. Unigenes were distributed into five major KEGG categories; Metabolism, Genetic Information Processing, Environmental Information Processing, Cellular Processes and Organismal Systems.

to produce major flavonoid groups such as chalcones, flavanones, flavones, flavan-4-ols, flavan-3-ols, flavanols, isoflavones and anthocyanins (Additional file 6 and Figure 7).

An overview of the flavonoid biosynthetic pathway leading to the synthesis of major flavonoid groups and the proposed panduratin A biosynthesis is shown in Figure 7. Initially, phenylalanine is deaminated by phenylalanine ammonia lyase (PAL; EC: 4.3.1.24) to produce first the phenylpropanoid acid, cinnamic acid. Then, cinnamic acid was either converted to cinnamoyl-CoA by 4coumaroyl:coenzyme A ligase (4CL; EC: 6.2.1.12) or converted to p-coumaric acid by a P450 cytochrome monoxygenase enzyme, cinnamate-4-hydroxylase $(\mathrm{C} 4 \mathrm{H}$; EC: 1.14.13.11). This was the first branching in the phenylpropanoid pathway. Subsequently, p-coumaric acid is also converted to phenolic CoA thioesters catalyzed by $4 \mathrm{CL}$ through attachment of CoA to a phenolic compound, producing p-coumaroyl-CoA.

Both phenolic CoA thioesters enter the flavonoid pathway and produce chalcones, which is the first flavonoid major group, by condensation of three acetate extender molecules from malonyl-CoA. The enzyme that is responsible for this reaction is chalcone synthase (CHS; EC: 2.3.1.74), a type III polyketide synthase [40]. Once produced, chalcones serve as the precursors for all of the various groups of flavonoids. Next, chalcone isomerase (CHI; EC: 5.5.1.6) converts chalcone into flavanone by isomerization. Flavanones are important intermediates, as they are involved in producing several other major flavonoid groups.

There are four major ways of producing various flavonoid groups by modifications of flavanones. Firstly, flavanones may be dehydrated to produce flavones by flavone synthase 1 (FS1; EC: 1.14.11.22) and 2 (FS2; EC: 1.14.11.22). Secondly, flavanones may also be further isomerized to form isoflavones by isoflavone synthase (ISF; EC: 1.14 .13 .136 ) in some plants, which are subsequently used to synthesize isoflavonoids. Thirdly, reduction reactions catalyzed by dihydroflavonol 4reductase (DFR; EC: 1.1.1.219/1.1.1.234) converting flavanones to flavan-4-ols, which serves as precursors to produce phlobaphene polymers. Lastly, flavanones may form dihydroflavonols by hydroxylation catalyzed by flavanone-3-hydroxylase (F3H; EC: 1.14.11.9). Dihydroflavonols are further converted to flavanols by a desaturation reaction catalyzed by flavonol synthase (FLS; EC: 1.14.11.23).

Dihydroflavonols are precursors for anthocyanin pigments synthesis which upon synthesis is reduced to 
Table 7 Summary of unigene distribution in KEGG pathways that has significant differential expression of genes

\begin{tabular}{|c|c|c|c|c|c|c|}
\hline Category & Sub-category & Pathway & $\begin{array}{l}\text { DEGs with } \\
\text { pathway } \\
\text { annotation }\end{array}$ & $\begin{array}{l}\text { Up-regulated } \\
\text { unigenes }\end{array}$ & $\begin{array}{c}\text { Down-regulated } \\
\text { unigenes }\end{array}$ & Q-value \\
\hline \multirow[t]{12}{*}{ Metabolism } & \multirow{6}{*}{$\begin{array}{l}\text { Carbohydrate } \\
\text { Metabolism }\end{array}$} & Citrate cycle (TCA cycle) & 102 & 14 & 88 & $9.60 \mathrm{E}-05$ \\
\hline & & Galactose metabolism & 73 & 18 & 55 & 1.43E-02 \\
\hline & & Glycolysis/Gluconeogenesis & 155 & 33 & 122 & $2.20 \mathrm{E}-02$ \\
\hline & & $\begin{array}{l}\text { Amino sugar and nucleotide } \\
\text { sugar metabolism }\end{array}$ & 151 & 56 & 95 & $3.04 \mathrm{E}-02$ \\
\hline & & Pyruvate metabolism & 134 & 18 & 116 & $3.04 \mathrm{E}-02$ \\
\hline & & $\begin{array}{l}\text { Glyoxylate and dicarboxylate } \\
\text { metabolism }\end{array}$ & 43 & 7 & 36 & $3.04 \mathrm{E}-02$ \\
\hline & Energy Metabolism & Nitrogen metabolism & 75 & 25 & 50 & $3.56 \mathrm{E}-03$ \\
\hline & \multirow[t]{3}{*}{ Amino Acid Metabolism } & Phenylalanine metabolism & 92 & 51 & 41 & 1.43E-02 \\
\hline & & $\begin{array}{l}\text { Alanine, aspartate and } \\
\text { glutamate metabolism }\end{array}$ & 80 & 20 & 60 & $3.04 \mathrm{E}-02$ \\
\hline & & $\begin{array}{l}\text { Valine, leucine and isoleucine } \\
\text { biosynthesis }\end{array}$ & 45 & 7 & 38 & 4.21E-02 \\
\hline & $\begin{array}{l}\text { Metabolism of Terpenoid } \\
\text { and Polyketides }\end{array}$ & Terpenoid backbone biosynthesis & 75 & 4 & 71 & 1.90E-06 \\
\hline & $\begin{array}{l}\text { Biosynthesis of Other } \\
\text { Secondary Metabolites }\end{array}$ & Phenylpropanoid biosynthesis & 163 & 68 & 95 & 1.43E-02 \\
\hline \multirow{2}{*}{$\begin{array}{l}\text { Genetic Information } \\
\text { Processing }\end{array}$} & Translation & Aminoacyl-tRNA biosynthesis & 96 & 10 & 86 & $2.44 \mathrm{E}-03$ \\
\hline & $\begin{array}{l}\text { Folding, Sorting and } \\
\text { Degradation }\end{array}$ & $\begin{array}{l}\text { Protein processing in } \\
\text { endoplasmic reticulum }\end{array}$ & 241 & 53 & 188 & $1.43 \mathrm{E}-02$ \\
\hline $\begin{array}{l}\text { Environmental Information } \\
\text { Processing }\end{array}$ & Membrane Transport & $\mathrm{ABC}$ transporters & 116 & 17 & 99 & $1.22 \mathrm{E}-07$ \\
\hline Cellular Processes & $\begin{array}{l}\text { Transport and } \\
\text { Catabolism }\end{array}$ & Endocytosis & 208 & 44 & 164 & 9.54E-04 \\
\hline
\end{tabular}

Pathways in KEGG that has significant differential expression of genes was determined by $\mathrm{Q}$ value $\leq 0.05$.

leucoanthocyanidins by dihydroflavonol 4-reductase (DFR) and converted to anthocyanidins by anthocyanidin synthase (ANS; EC: 1.14.11.19). Finally, anthocyanins are synthesized from anthocyanidins through further modifications. Leucoanthocyanidins and anthocyanidins are reduced to form flavan-3-ols by leucoanthocyanidin reductase (LAR; EC: 1.17.1.3) and anthocyanidin reductase (ANR; EC: 1.3.1.77) respectively which then serve as polymers producing proanthocyanidins.

Figure 7 shows the regulation patterns of unigenes that were mapped to the main enzymes in the flavonoid pathway. Only PAL, C4H, 4CL, CHS, CHI, F3H, FLS, DFR, ANS and LAR were mapped to the Boesenbergia rotunda transcriptome unigenes. However, no gene regulation was detected for $\mathrm{CHI}$ (Table 10). In contrast, no unigene matched for FS1/FS2 and ANR (Table 9). Additionally, the isoflavone biosynthetic pathway map was not present in the Boesenbergia rotunda system. In total, there were 14 unigenes mapped to PAL but only 2 of them showed up-regulation while 5 were downregulated (Table 8). Out of 14 unigenes assigned as $\mathrm{C} 4 \mathrm{H}$, only 1 unigene was up-regulated and the other 3 unigenes were down-regulated. The most abundant unigene was assigned as 4CL with 44 unigenes. However, only 3 were up-regulated, while 15 others were down-regulated. A further 25 unigenes were assigned as $\mathrm{CHS}$ but only one unigene was up-regulated while 7 were downregulated during production of chalcones in the flavonoid pathway. There was no gene regulation pattern observed during flavanone production from chalcones by $\mathrm{CHI}$. A non-enzymatic reaction is suggested to be involved in this step. Subsequently, only two F3H and five FLS unigenes were up-regulated to form flavonols from flavanones. In contrast, there were four down-regulated DFR, three up-regulated ANS and one down-regulated LAR unigenes involved in anthocyanin and proanthocyanidin production.

Based on gene regulation patterns in the flavonoid biosynthetic pathway, the highest up-regulated expression level was Unigene49558_All with 3.8 fold higher compared to control (Table 10). This unigene was annotated as F3H, FLSand ANS. The second highest up-regulated gene was Unigene41852_All, which annotated as 4CL which showed a 2.2 fold change. The rest of the unigenes in the flavonoid pathway were 1 to 1.8 fold upregulated. The most down-regulated expression in the 


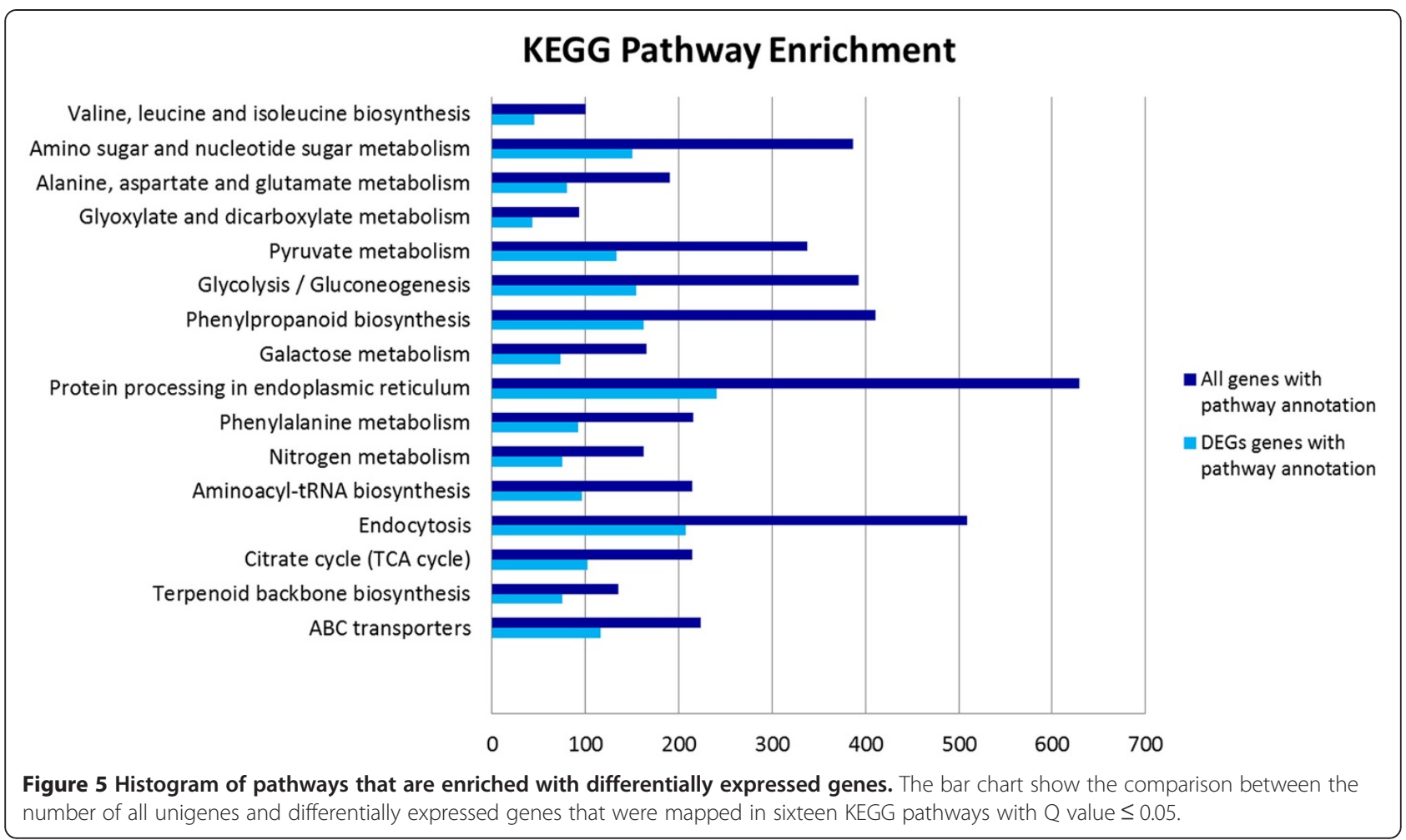

flavonoid pathway was 4CL with seven out of fifteen unigenes showing expression levels between 2 to 3.3 fold lower than the control (Table 10). The unigenes included Unigene88072_All, Unigene37844_All, Unigene68813_All, Unigene44539_All, Unigene51006_All, Unigene32973_All and Unigene85725_All. Three other unigenes that showed more than 2 fold down-regulation was $\mathrm{C} 4 \mathrm{H}$ (Unigene17324_All) with 2.5 fold, CHS (Unigene35484_All) with 2.2 fold and DFR (Unigene100192_All) with 2.8 fold. The expression levels of the remaining down-

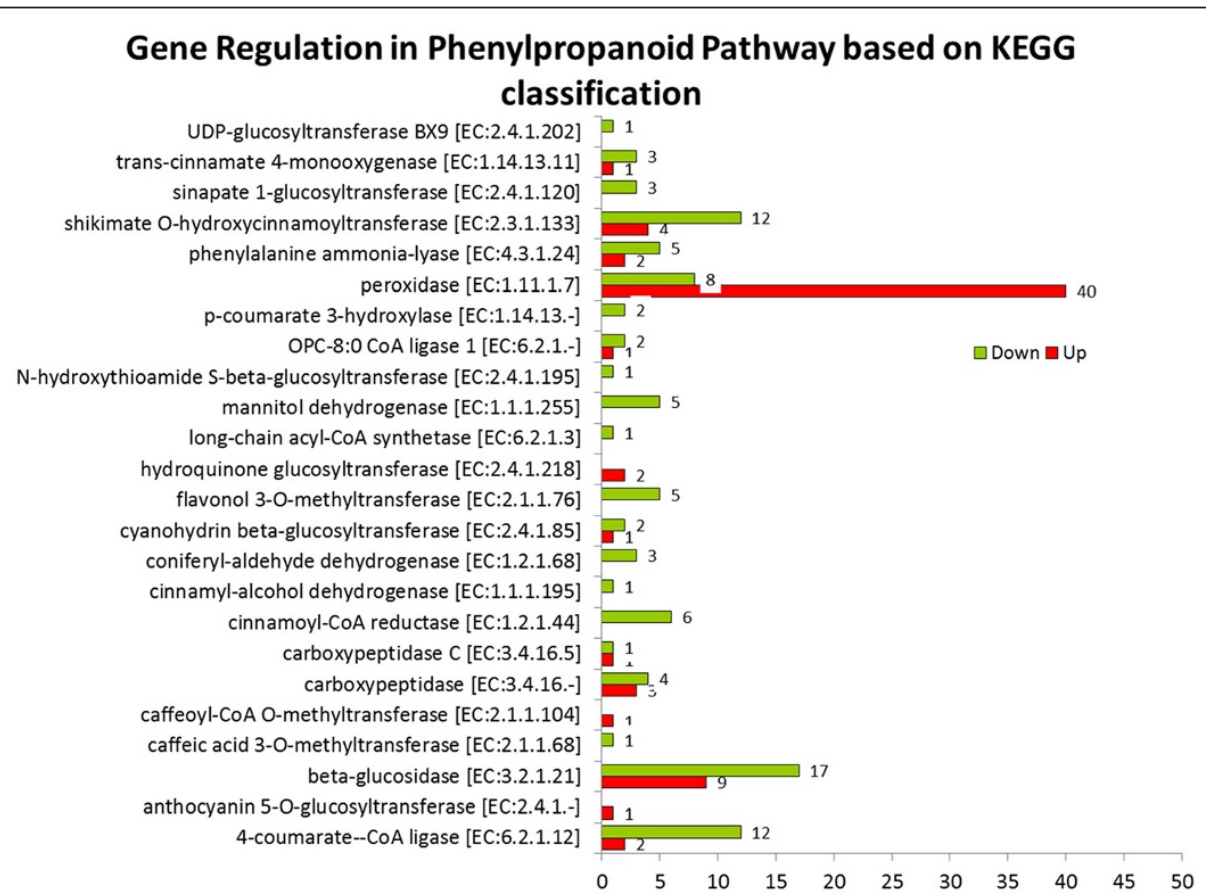

Figure 6 Histogram of gene regulation in phenylpropanoid pathway based on KEGG database classification. 
Table 8 Unigenes potentially related to panduratin A biosynthesis in phenylpropanoid pathway

\begin{tabular}{|c|c|c|c|c|c|c|}
\hline Enzyme name & $\begin{array}{l}\text { Abbreviations in the flavanoid } \\
\text { pathway (Figure 7) }\end{array}$ & $\begin{array}{c}\mathrm{EC} \\
\text { number }\end{array}$ & Enzyme class & $\begin{array}{c}\text { Total } \\
\text { unigene }\end{array}$ & $\begin{array}{l}\text { Up- } \\
\text { regulated }\end{array}$ & $\begin{array}{l}\text { Down- } \\
\text { regulated }\end{array}$ \\
\hline \multicolumn{7}{|l|}{ Phenylpropanoid pathway } \\
\hline cinnamyl-alcohol dehydrogenase & - & 1.1.1.195 & Oxidoreductase & 10 & 0 & 6 \\
\hline peroxidase & - & 1.11.1.7 & Oxidoreductase & 90 & 40 & 8 \\
\hline ferulate-5-hydroxylase & - & 1.14.-- & Oxidoreductase & 4 & 0 & 0 \\
\hline p-coumarate 3-hydroxylase & - & 1.14.13.- & Oxidoreductase & 5 & 0 & 2 \\
\hline trans-cinnamate 4-monooxygenase & $\mathrm{C} 4 \mathrm{H}$ & 1.14.13.11 & Oxidoreductase & 14 & 1 & 3 \\
\hline cinnamoyl-CoA reductase & - & 1.2.1.44 & Oxidoreductase & 18 & 0 & 6 \\
\hline coniferyl-aldehyde dehydrogenase & - & 1.2.1.68 & Oxidoreductase & 6 & 0 & 3 \\
\hline $\begin{array}{l}\text { putative caffeoyl-CoA 3-O- } \\
\text { methyltransferase }\end{array}$ & - & 2.1.1.- & Transferase & 2 & 0 & 0 \\
\hline caffeoyl-CoA O-methyltransferase & - & 2.1.1.104 & Transferase & 2 & 1 & 0 \\
\hline caffeic acid 3-O-methyltransferase & - & 2.1.1.68 & Transferase & 14 & 0 & 6 \\
\hline $\begin{array}{l}\text { shikimate O- } \\
\text { hydroxycinnamoyltransferase }\end{array}$ & - & 2.3.1.133 & Transferase & 43 & 4 & 12 \\
\hline $\begin{array}{l}\text { sinapoylglucose-choline } \\
\text { O-sinapoyltransferase }\end{array}$ & - & 2.3.1.91 & Transferase & 13 & 0 & 0 \\
\hline $\begin{array}{l}\text { sinapoylglucose-malate } \\
\text { O-sinapoyltransferase }\end{array}$ & - & 2.3.1.92 & Transferase & 7 & 0 & 0 \\
\hline coniferyl-alcohol glucosyltransferase & - & 2.4.1.111 & Transferase & 24 & 0 & 0 \\
\hline sinapate 1-glucosyltransferase & - & 2.4.1.120 & Transferase & 29 & 1 & 5 \\
\hline beta-glucosidase & - & 3.2.1.21 & Hydrolase & 76 & 9 & 17 \\
\hline phenylalanine ammonia-lyase & PAL & 4.3.1.24 & Lyase & 14 & 2 & 5 \\
\hline phenylalanine/tyrosine ammonia-lyase & - & 4.3.1.25 & Lyase & 1 & 0 & 0 \\
\hline 4-coumarate-CoA ligase & $4 C L$ & 6.2.1.12 & Ligase & 44 & 3 & 15 \\
\hline
\end{tabular}

One unigene may map to more than one enzyme in the pathway. The Table shows all unigenes that are mapped to specific enzymes and gene regulation patterns either up-, down-regulated or both.

regulated unigenes were in between 1 to 2 fold downregulated.

\section{Further analysis on COG clusters}

Further analysis on the secondary metabolite cluster (Figure 8) and defense mechanism cluster (Figure 9) that was classified using the COG database, was carried out. Out of 16,426 unigenes that were assigned through the COG database, 171 unigenes were clustered in the secondary metabolite cluster with 90 up-regulated and 81 down-regulated unigenes respectively. In the secondary metabolite cluster, the highest number of up-regulated unigenes were RTX toxin and and related $\mathrm{Ca} 2+$ binding proteins with 35 unigenes, followed by cytochrome P450 (20 unigenes) and putative multicopper oxidases (11 unigenes). While the highest number of down-regulated unigenes were RTX toxin and and related $\mathrm{Ca} 2+$ binding proteins with 22 unigenes, followed by cytochrome $\mathrm{P} 450$ (20 unigenes) and SAM-dependent methyltransferases (10 unigenes).

In total, there were 152 unigenes that were mapped into the defense mechanism cluster in the COG database, with 31 and 121 up-regulated and downregulated unigenes respectively. In the defense mechanism cluster, the highest down-regulated unigenes were $A B C$ type multidrug system, ATPase and permease components with 60 unigenes and $\mathrm{ABC}$-type multidrug system, ATPase components with 27 unigenes.

\section{Experimental validation}

The qPCR results of 9 randomly selected unigenes showed general agreement with their transcript abundance changes as determined by RNA-seq, suggesting the reliability of the transcriptome profiling data (Figure 10). For the unigenes tested only two showed some discrepancies although both were similarly up-regulated i.e Unigene58054_All showed a much higher expression level while Unigene1735_All had moderately higher expression in qPCR as compared to the RNA-seq results.

\section{Discussion}

Digital gene expression (DGE) analysis for elucidating differentially expressed genes (DEGs) is an approach that can be used to further understand the nature of a plant's 
Table 9 Unigenes potentially related to panduratin A biosynthesis in the flavonoid pathway

\begin{tabular}{|c|c|c|c|c|c|c|}
\hline Enzyme name & $\begin{array}{l}\text { Abbreviations in flavanoid } \\
\text { pathway (Figure 7) }\end{array}$ & EC number & Enzyme class & $\begin{array}{c}\text { Total } \\
\text { unigene }\end{array}$ & $\begin{array}{l}\text { Up- } \\
\text { regulated }\end{array}$ & $\begin{array}{l}\text { Down- } \\
\text { regulated }\end{array}$ \\
\hline \multicolumn{7}{|l|}{ Flavonoid pathway } \\
\hline $\begin{array}{l}\text { bifunctional dihydroflavonol 4-reductase/ } \\
\text { flavanone 4-reductase }\end{array}$ & DFR & $\begin{array}{l}1.1 .1 .219 / \\
1.1 .1 .234\end{array}$ & Oxidoreductase & 15 & 0 & 4 \\
\hline $\begin{array}{l}\text { leucoanthocyanidin dioxygenase/ } \\
\text { anthocyanin synthase }\end{array}$ & ANS & 1.14.11.19 & Oxidoreductase & 16 & 3 & 4 \\
\hline flavone synthase & FS1/FS2 & 1.14.11.22 & Oxidoreductase & 0 & 0 & 0 \\
\hline flavonol synthase & FLS & 1.14.11.23 & Oxidoreductase & 29 & 5 & 6 \\
\hline $\begin{array}{l}\text { naringenin 3-dioxygenase/flavanone-3- } \\
\text { hydroxylase }\end{array}$ & $\mathrm{F} 3 \mathrm{H}$ & 1.14 .11 .9 & Oxidoreductase & 20 & 2 & 5 \\
\hline p-coumarate 3-hydroxylase & - & 1.14.13.- & Oxidoreductase & 5 & 0 & 2 \\
\hline trans-cinnamate 4-monooxygenase & $\mathrm{C} 4 \mathrm{H}$ & 1.14.13.11 & Oxidoreductase & 14 & 1 & 3 \\
\hline flavonoid 3'-monooxygenase & - & 1.14.13.21 & Oxidoreductase & 15 & 0 & 5 \\
\hline $\begin{array}{l}\text { cytochrome P450, family } 75 \text {, subfamily A } \\
\text { (flavonoid } 3^{\prime}, 5^{\prime} \text {-hydroxylase) }\end{array}$ & - & 1.14.13.88 & Oxidoreductase & 6 & 0 & 2 \\
\hline leucoanthocyanidin reductase & LAR & 1.17.1.3 & Oxidoreductase & 4 & 0 & 1 \\
\hline anthocyanin reductase & ANR & 1.3.1.77 & Oxidoreductase & 0 & 0 & 0 \\
\hline caffeoyl-CoA O-methyltransferase & - & 2.1.1.104 & Transferase & 2 & 1 & 0 \\
\hline shikimate O-hydroxycinnamoyltransferase & - & 2.3.1.133 & Transferase & 43 & 4 & 12 \\
\hline 6'-deoxychalcone synthase & - & 2.3.1.170 & Transferase & 15 & 0 & 0 \\
\hline chalcone synthase & $\mathrm{CHS}$ & 2.3.1.74 & Transferase & 25 & 1 & 7 \\
\hline chalcone isomerase & $\mathrm{CHI}$ & 5.5 .1 .6 & Isomerase & 2 & 0 & 0 \\
\hline
\end{tabular}

One unigene may map to more than one enzyme in the pathway. The table shows the all unigenes that are mapped to specific enzymes and gene regulation patterns either up-, down-regulated or both.

response towards various stimuli or stresses [41]. For medicinal plants, RNA-Seq together with DEGs data has been used to identify genes that are directly or indirectly involved in the biosynthetic pathways of target bioactive compounds. Thus far, cytochrome P450 (CYP450) had been identified in most reported analysis of late terpenoid pathways. The combination of RNA-Seq technology and methyl jasmonate induction experiments successfully identified one CYP450 and four glycosyltransferases as key enzymes in the ginsenoside biosynthesis in Panax quinquefolius [42]. Subsequently, by combining RNASeq technology and phylogenetic tree analysis based on the previously identified CYP450 and glycosyltransferase in Panax quinquefolius, two CYP450 and one UDPglycosyltransferase were also elucidated as candidates for ginsenoside biosynthesis in Panax notoginseng [42,43]. Additionally, seven CYP450 and five glucosyltransferase were identified in mogrosides biosynthesis in Siraitia grosvenorri; and six CYP450 and one glucosidase identified in camptothecin biosynthesis in Camtotheca acuminate $[44,45]$. Additionally, RNAseq analysis from different rhizomes of cultivated Curcuma longa cultivars in India described transcripts potentially related to anticancer and antimalarial terpenoids [46].
This strategy was also used to elucidate the candidate genes that might be involved in the panduratin A biosynthesis through sequencing of the whole transcriptome of untreated and phenylalanine treated cell suspension cultures of Boesenbergia rotunda and analysis of the gene expression patterns involved in the phenylpropanoid and flavonoid pathways. In total, there were 24, 473, 594 and 23, 470, 648 reads that were successfully generated from control and phenylalanine treated Boesenbergia rotunda respectively using an Illumina-Solexa sequencer (Table 1). Using SOAPdenovo software, these unigenes were overlapped and assembled to form longer sequences from short reads to contigs, scaffolds and unigenes, which resulted in 101, 043 Boesenbergia rotunda unigenes successfully assembled. However, only $50.41 \%$ unigenes were successfully annotated in the public protein databases with $49.93 \%$ in NR, followed by $34.63 \%$ in Swiss-Prot, $24.07 \%$ in KEGG and $16.26 \%$ in COG (Table 2). The limited numbers of identified plant genes and their deposition in the database might be the reason for the unannotated $49.59 \%$ of the transcriptome unigenes. These unannotated unigenes should be further identified to enrich public plant databases. 


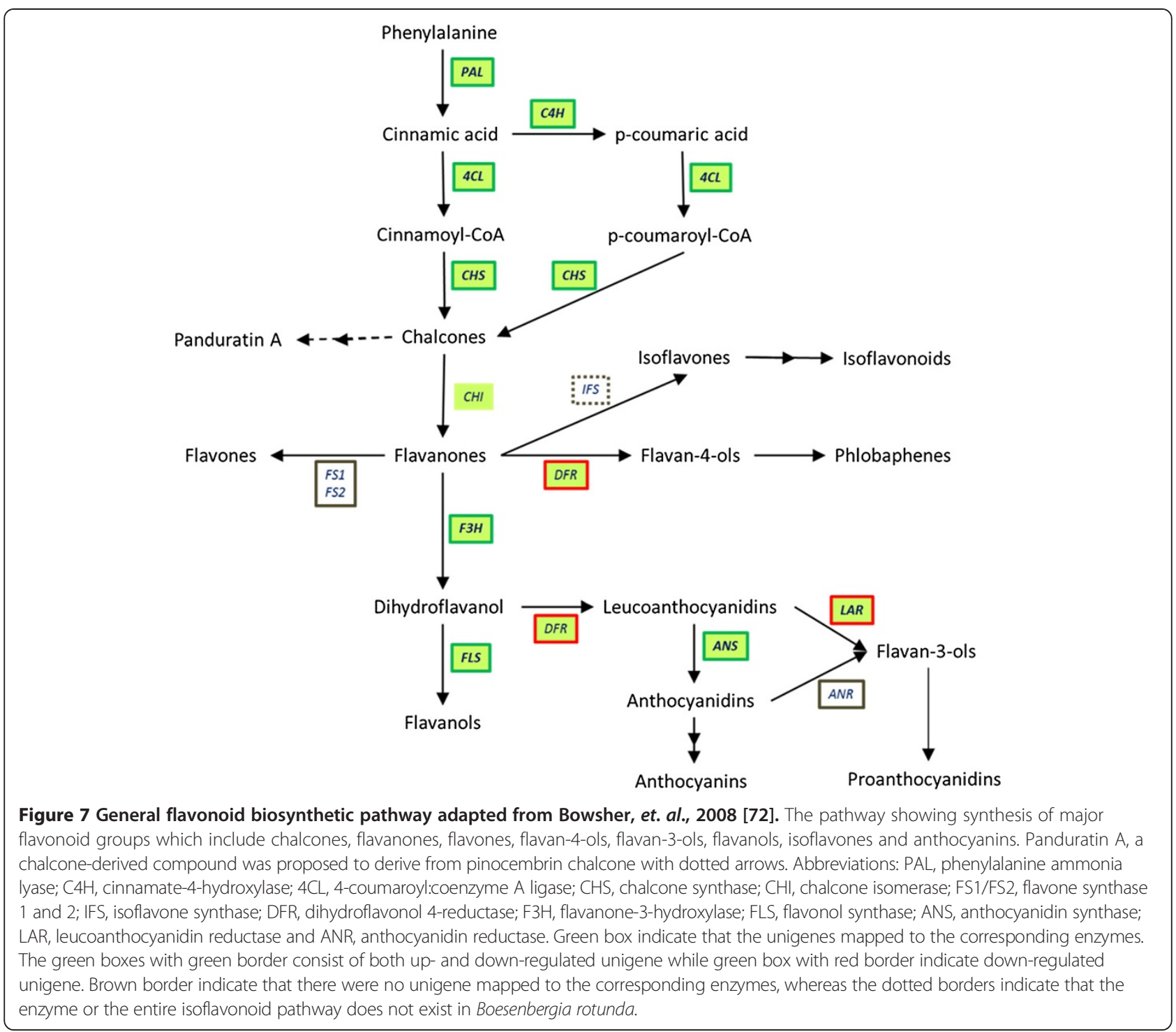

In future, further study using mutant yeast complementation experiments will be conducted to determine the unigene functions. This complementary experimental approach is based on employing the specific mutant yeast that cannot grow on certain media composition. However, mutant yeast harbouring the gene of interest could grow on the selectable media due to their ability to restore the physical deficiency of the mutated yeast [47-50], in which consequently indirectly verify their gene function. The functional complementary approach using mutant yeast has successfully elucidated genes in Arabidopsis thaliana such as isopenthyl diphosphate isomerase encoded by the IPP gene, methyltransferase encoded by the COQ3 gene, phosphor-ethanilamine Nmethyltransferase and acetylornithine aminotransferase encoded by the TUP5 gene [47-50]. The same approach has also elucidated iron transporter gene function (MxIRT1) in Malus xiaojinesis [51].

Phenylalanine was chosen as an exogenous precursor to increase panduratin A production in Boesenbergia rotunda cell suspension culture at fourteen-days post treatment with phenylalanine [35]. The strategy was based on increasing the key compound within the phenylpropanoid biosynthetic pathway that would induce or increase the yield of the final product. The addition of phenylalanine was also reported to stimulate taxol production in Taxus cupidata cell suspension culture [52,53].

Differential expression patterns of transcriptome profile between control and phenylalanine treated Boesenbergia rotunda cell suspension culture showed 14, 644 significantly up-regulated and 14, 379 significantly downregulated unigenes with FDR $\leq 0.001$ and $\mid \log _{2}$ Ratio $\mid \geq 1$ 
Table 10 Gene regulation patterns in the flavonoid pathway

\begin{tabular}{|c|c|c|c|c|c|}
\hline \multirow{2}{*}{ Enzyme } & \multirow{2}{*}{$\begin{array}{c}\text { EC } \\
\text { number }\end{array}$} & \multicolumn{2}{|c|}{ Up-regulated } & \multicolumn{2}{|c|}{ Down-regulated } \\
\hline & & Unigene ID & Expression level fold & Unigene ID & Expression level fold \\
\hline \multirow[t]{5}{*}{ PAL } & 4.3.1.24 & Unigene10327_All & 1.1 & Unigene83336_All & -1.9 \\
\hline & & Unigene89418_All & 1 & Unigene56631_All & -1.9 \\
\hline & & & & Unigene64872_All & -1.6 \\
\hline & & & & Unigene619_All & -1.3 \\
\hline & & & & Unigene9322_All & -1 \\
\hline \multirow[t]{3}{*}{$\mathrm{C} 4 \mathrm{H}$} & 1.14.13.11 & Unigene67845_All & 1.4 & Unigene17324_All & -2.5 \\
\hline & & & & Unigene11543_All & -1.7 \\
\hline & & & & Unigene93243_All & -1.1 \\
\hline \multirow[t]{15}{*}{$4 \mathrm{CL}$} & 6.2.1.12 & Unigene41852_All & 2.2 & Unigene88072_All & -3.3 \\
\hline & & Unigene36813_All & 1.2 & Unigene37844_All & -3 \\
\hline & & Unigene3277_All & 1.1 & Unigene68813_All & -2.8 \\
\hline & & & & Unigene44539_All & -2.3 \\
\hline & & & & Unigene51006_All & -2.2 \\
\hline & & & & Unigene32973_All & -2.1 \\
\hline & & & & Unigene85725_All & -2 \\
\hline & & & & Unigene28297_All & -1.9 \\
\hline & & & & Unigene57823_All & -1.8 \\
\hline & & & & Unigene520_All & -1.7 \\
\hline & & & & Unigene19555_All & -1.7 \\
\hline & & & & Unigene20812_All & -1.5 \\
\hline & & & & Unigene10021_All & -1.4 \\
\hline & & & & Unigene6803_All & -1.4 \\
\hline & & & & Unigene20574_All & -1.4 \\
\hline \multirow[t]{7}{*}{$\mathrm{CHS}$} & 2.3.1.74 & Unigene1735_All & 1.5 & Unigene35484_All & -2.2 \\
\hline & & & & Unigene31906_All & -1.8 \\
\hline & & & & Unigene37184_All & -1.4 \\
\hline & & & & Unigene33635_All & -1.3 \\
\hline & & & & Unigene63145_All & -1.3 \\
\hline & & & & Unigene55042_All & -1.1 \\
\hline & & & & Unigene29406_All & -1.1 \\
\hline \multirow[t]{5}{*}{$\mathrm{F} 3 \mathrm{H}$} & 1.14.11.9 & Unigene49558_All & 3.8 & Unigene100816_All & -1.6 \\
\hline & & Unigene5973_All & 1.4 & Unigene4657_All & -1.6 \\
\hline & & & & Unigene22973_All & -1.4 \\
\hline & & & & Unigene4884_All & -1.3 \\
\hline & & & & Unigene23932_All & -1.1 \\
\hline \multirow[t]{6}{*}{ FLS } & 1.14.11.23 & Unigene49558_All & 3.8 & Unigene100816_All & -1.6 \\
\hline & & Unigene89505_All & 1.8 & Unigene4657_All & -1.6 \\
\hline & & Unigene56837_All & 1.8 & Unigene22973_All & -1.4 \\
\hline & & Unigene26406_All & 1.6 & Unigene4884_All & -1.3 \\
\hline & & Unigene5973_All & 1.4 & Unigene23932_All & -1.1 \\
\hline & & & & Unigene33774_All & -1 \\
\hline \multirow[t]{2}{*}{ DFR } & 1.1.1.219 & & & Unigene100192_All & -2.8 \\
\hline & & & & Unigene40110_All & -1.9 \\
\hline
\end{tabular}


Table 10 Gene regulation patterns in the flavonoid pathway (Continued)

\begin{tabular}{|c|c|c|c|c|c|}
\hline & & & & Unigene84008_All & -1.7 \\
\hline & & & & Unigene49734_All & -1.3 \\
\hline \multirow[t]{4}{*}{ ANS } & 1.14.11.19 & Unigene49558_All & 3.8 & Nigene100816_All & -1.6 \\
\hline & & Unigene89505_All & 1.8 & Unigene4657_All & -1.6 \\
\hline & & Unigene56837_All & 1.8 & Unigene4884_All & -1.3 \\
\hline & & & & Unigene30270_All & -1.1 \\
\hline LAR & 1.17.1.3 & & & Unigene73982_All & -1 \\
\hline
\end{tabular}

The genes include phenylalanine ammonia lyase (PAL), cinnamate-4-hydroxylase (C4H), 4-coumarate-CoA ligase (4CL), chalcone synthase (CHS), favanone-3hydroxylase (F3H), flavonol synthase (FLS), dihydroflavonol-4-reductase (DFR), anthocyanin synthase (ANS) and leucoanthocyanidin reductase (LAR).

(Figure 3). The key factor of differential gene expression in Boesenbergia rotunda cell suspension culture between control and phenylalanine treated is proposed to be related to the differential expression of transcription factors and transcription regulators. Transcription factors are regulatory proteins that control the expression of specific groups of genes through sequence-specific DNA binding and protein-protein interactions. They act either as activators or repressors of gene expression, mediating either an increase or decrease in the accumulation of mRNA depending on tissue type or in response to internal or external signals $[54,55]$. Both transcription factors and transcription regulators in the phenylalanine treated samples were initially regulated by the addition of phenylalanine and appear to result in regulation of other genes.

There were in total 139 transcription factors and 46 transcription regulators found in Boesenbergia rotunda in this study. The classification of both transcription factors and regulators were carried out by homology BlastX search against the rice database using iTAK software. The most abundant transcription factor found was classified under the $\mathrm{C} 3 \mathrm{H}$ family. The second most abundant transcription factor found was MYB followed by NAC, WRKY, bZIP and AP2-EREBP family (Table 4). All of these transcription factor families except for $\mathrm{CH} 3$ showed significant differential expression of their members in the treated sample (FDR $\leq 0.001$ and $\mid \log _{2}$ Ratio $\mid \geq 1$ ), suggesting that they played an important role in the induction or repression of the panduratin A biosynthesis pathway.

It was reported that plant R2R3 MYB transcription factor contain two helix-turn-helix motifs responsible for binding to target genes [56]. The R2R3 MYB family plays a major role in regulating sets of genes that are responsible for secondary metabolite biosynthetic pathways in plants especially for synthesizing flavonoids in the phenylpropanoid pathway [54]. Similarly it was

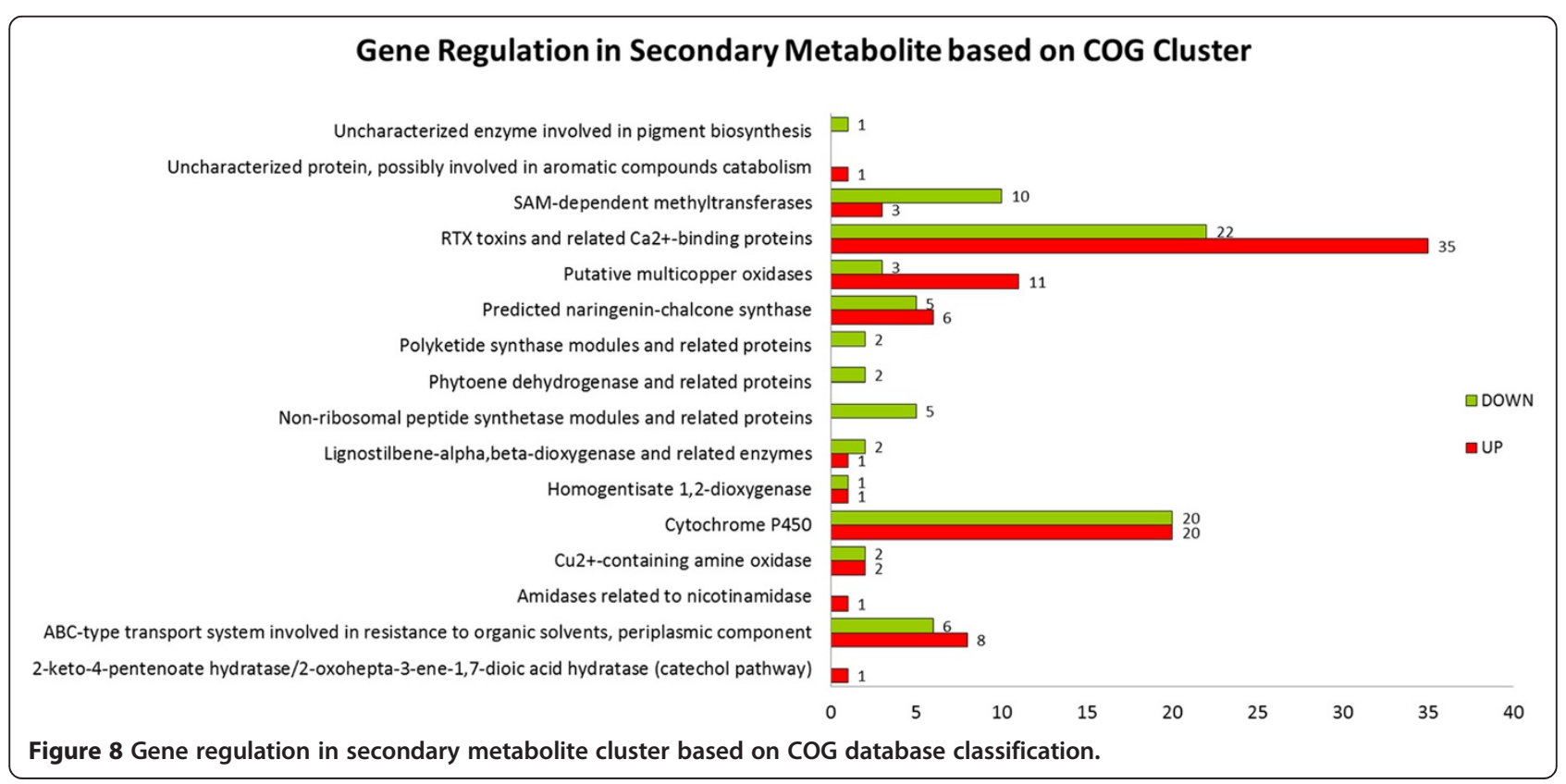




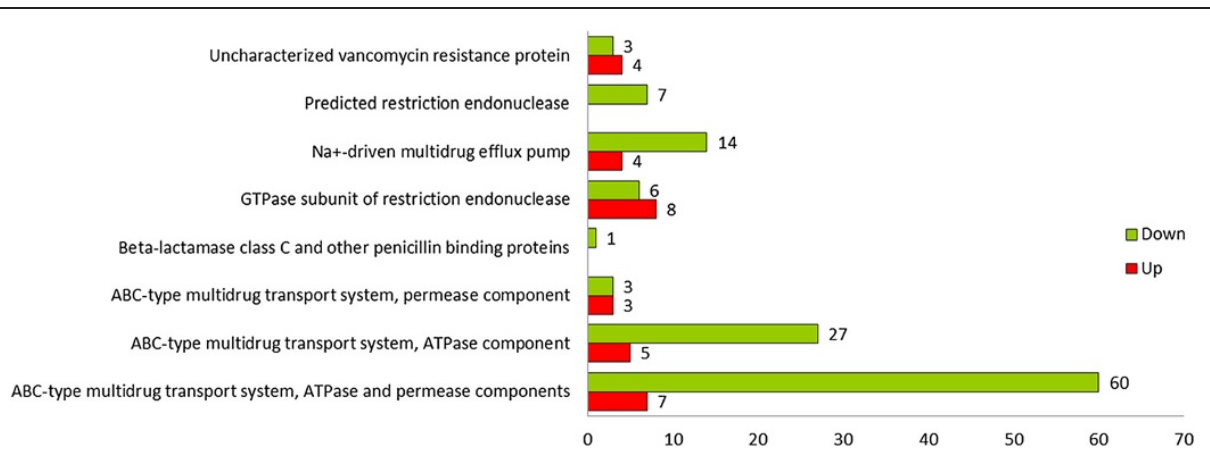

Figure 9 Gene regulation in defence mechanism cluster based on COG database classification.

apparent that MYB transcription factors were affected in this study. Although only one MYB gene was upregulated, the remaining four were down-regulated and were possibly responsible for down regulating or switching off sets of genes that were not related to the panduratin A biosynthetic pathway. Other up-regulated transcription factors such as AP2-EREBP, WRKY, bZIP, GRAS and NAC haves been reported to modulate the genes for plant growth and plant response to biotic or abiotic stresses [57-61]. This information would be useful for future analysis on genes that are regulated by these transcription factors especially in relation to phenylpropanoid and flavonoid pathways.
The addition of exogenous phenylalanine in the liquid media of treated cell suspension culture helps to elucidate genes that might be directly or indirectly responsible for panduratin A biosynthesis. The most abundant up-regulated unigenes in the phenylpropanoid pathway were peroxidase, with 40 out of 90 unigenes (Table 8). Peroxidase is classified as a class III plant peroxidase that catalyzes plant-specific oxidoreduction between hydrogen peroxide $\left(\mathrm{H}_{2} \mathrm{O}_{2}\right)$ and various reductants [62]. Differential expression profile of the peroxidase as isoenzymes in Boesenbergia rotunda suggests that they might be involved in catalyzing different substrate and may be involved in different physiological processes.

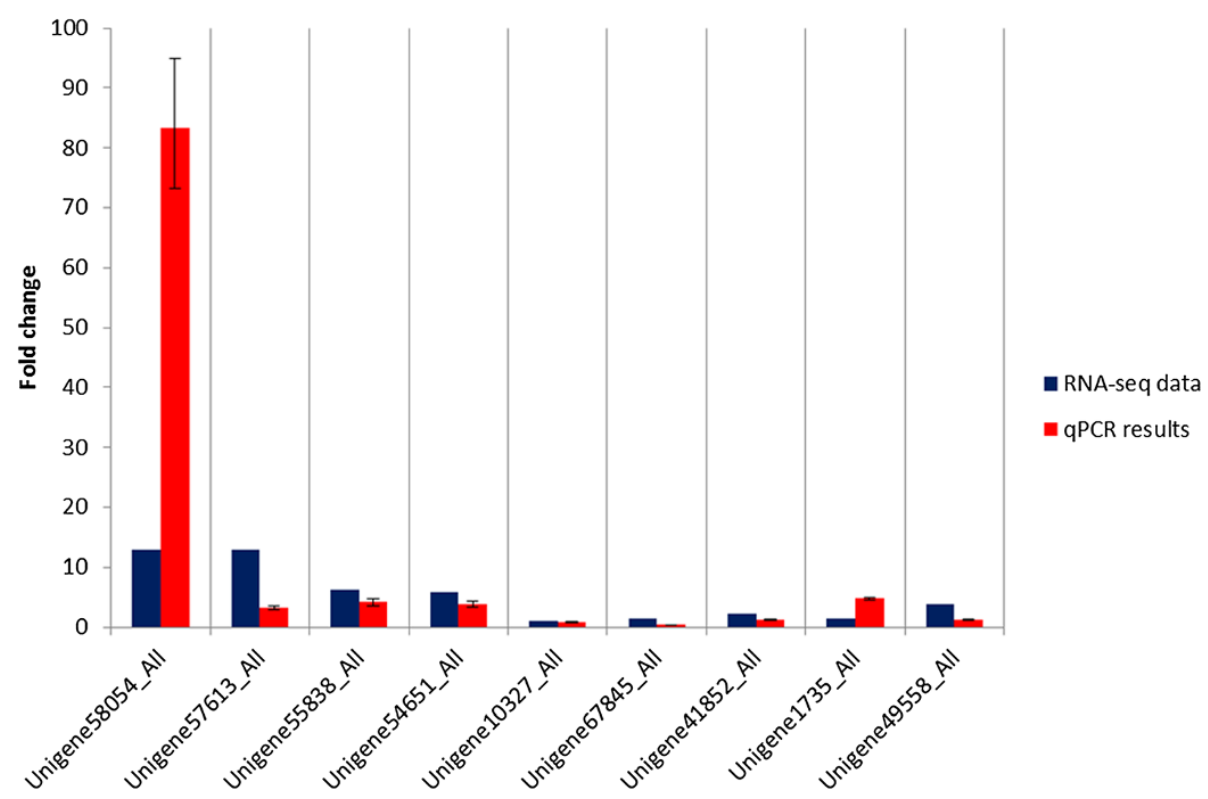

Figure 10 Expression pattern validation of selected unigenes by qPCR. Changes in transcript levels of 9 selected unigenes. X-axis shows fold changes in transcript abundance of unigenes. Blue bar indicates transcript abundance changes calculated by the RPKM method. Red bar with associated standard error bar represents relative expression level determined by qPCR using $2^{-\triangle \Delta C T}$ method. Results represent mean standard deviations $( \pm S D)$ of four experimental replicates. 
Peroxidase class III is involved in lignification in higher plants by radical coupling of monolignols [63]. This oxidoreduction reaction utilizes hydrogen peroxide $\left(\mathrm{H}_{2} \mathrm{O}_{2}\right)$ for oxidative power to produce monolignol radicals for lignin polymerization [63]. Different monolignols in this reaction produces different types of lignin and thus provide different resistance barriers for plants. Lignin provides mechanical strength and resistance against pathogens in plants. Lignification is a normal process for plant growth and development and also occurs in response to environmental stresses [64]. Additionally, some peroxidase isoenzymes were regulated upon environmental stimuli or prior attack by pathogens, which render the plant with self-defense mechanism against physical, chemical and biological stresses [65].

Most primary metabolic processes such as carbohydrate metabolism, energy metabolism and amino acid metabolism have more down-regulated unigenes compared to up-regulated unigenes in the same pathway $\left(\right.$ FDR $\leq 0.001$ and $\mid \log _{2}$ Ratio $\mid \geq 1$ ) (Table 7 ). Primary metabolism is essential for plant growth, plant development and plant reproduction. In cell suspension cultures, primary metabolism is essential for plant cells to propagate in liquid media. Down-regulation of unigenes in the primary metabolic pathways after 14 days of propagation might be due to depleted nutrients in the liquid media. It can be suggested that by depleting plant nutrients, cell suspension cultures are stressed and eventually induces secondary metabolites. Similar observations were reported by Lattanzio et. al. who showed that under limited nutrient conditions, increased phenolic compounds was observed with a decrease in biomass production [66].

There are several hypotheses that relates the carbon limiting step in primary metabolism to secondary metabolite production in plants as a trade-off between growth and the production of carbon-based secondary metabolites such as phenolic compounds $[67,68]$. The carbonnutrient hypothesis $(\mathrm{CNBH})$ suggests that plants modify the allocation of carbon skeletons between primary and secondary metabolism, where in a nutrient depletion situation, the plant restricts growth and the carbon skeleton is allocated to produce phenolic secondary metabolite compounds [68]. In addition, the protein competition model of phenolic allocation by Jones and Hartley, 1999 suggests that protein and phenolic synthesis are competing for the use of phenylalanine as a precursor [69]. Therefore, the availability of phenylalanine for phenolic compound biosynthesis is affected by any environmental changes that affect plant growth and protein synthesis.

In order to validate the transcriptome data, qPCR validation was done using a random selection of unigenes and included some of the unigenes that were annotated from the flavonoid pathway. This included PAL;
Unigen10327_All, C4H; Unigene67845_All, 4CL; Unigene41852_All, CHS; Unigene1735_All and F3H; Unigene49558_All (Figure 10).

Figure 7 shows the proposed panduratin A biosynthetic pathway, which is derived from chalcones in the flavonoid pathway. Through RNA-Seq and differentially expressed genes analysis, genes that are potentially involved in panduratin A synthesis were identified (Tables 8 and 9). From the results, it can be inferred that the isoflavanoids biosynthetic pathway may not be present in Boesenbergia rotunda as the pathway map was not found in the KEGG results. Additionally, there was no unigene mapped to flavone synthase (FS), suggesting that flavones were not produced in the Boesenbergia rotunda cell suspension culture. However, in contrast, flavones were successfully isolated and identified in black rhizome of Boesenbergia pandurata [70,71]. Tuchinda et. al. (2002), reported that Boesenbergia pandurata which is Boesenbergia rotunda's synonym has four rhizome varieties including yellow, black, white and red rhizomes [23]. From the transcriptome data, it could be suggested that different rhizomes varieties may have different flavonoid biosynthesis pathways as the source of cell suspension culture in this study originated from yellow rhizomes and this would merit further investigation. The other enzyme that had no unigene mapped to it was anthocyanine reductase (ANR), which converts anthocyanidins to flavan-3-ols, which eventually polymerizes to form proanthocyanidins.

The other enzymes in the flavonoid pathway consist of both up- and down-regulated unigenes except for chalcone isomerase (CHI), dihydroflavonol-4-reductase (DFR) and leucoanthocyanidin reductase (LAR) (Figure 7). There were no significant gene regulation patterns in $\mathrm{CHI}$, whereas down-regulated unigenes were identified for both DFR and LAR (Table 9). Most of unigenes that were mapped to the remaining flavonoid enzymes such as phenylalanine ammonia-lyase (PAL), cinnamate-4hydroxylase $(\mathrm{C} 4 \mathrm{H}), 4$-coumaroyl:coenzyme A ligase (4CL), chalcone synthase (CHS), flavanone-3-hydroxylase (F3H), flavonol synthase (FLS) and anthocyanin synthase (ANS) were down-regulated. It is suggested that down-regulation of enzymes isomers in the flavonoid pathway causes switch-off of competitive pathways and eventually divertion of the metabolic flux to the production of the desired secondary metabolites.

There were three enzymes known to be directly involved in panduratin A production, PAL, 4CL and CHS (Figure 7) [72]. All of these enzymes are known to be encoded by a multi-gene family. Phenylalanine ammonialyase (PAL) catalyzes the first step in phenylpropanoid biosynthetic pathway. In many plant species, several copies of the $P A L$ gene have been found and characterized. Between 2 to $4 P A L$ genes have been identified in Arabidopsis, 
tobacco, bean and parsley [73-76]. More than $40 P A L$ genes were identified in potato [77]. Although more than one $P A L$ gene is present in each plant species, the regulation of each $P A L$ gene depends on different response of stimuli [73]. In this study, there were 14 unigenes that were mapped as PAL. However, only 2 unigenes were up-regulated in response to the addition of phenylalanine.

A second enzyme 4CL, showed a gene regulation pattern directly involved in the panduratin A production. There were in total 44 unigenes mapped as $4 \mathrm{CL}$ in Boesenbergia rotunda. However, only 3 unigenes were up-regulated and 15 unigenes down-regulated after 14 days post treatment with phenylalanine. 4CL can be divided into two types in Arabidopsis thaliana; type I is responsible for lignin formation and type II leads to branching of the flavonoid pathways to produce flower pigments and defence mechanisms [78]. However, in rice, other than type I 4CL cluster, none were clustered in type II, but instead clustered separately in type III [79]. Although type I 4CL in dicots and type III 4CL in monocots are suggested to lead to lignin formation, they differ in sequences and substrate preference [79]. Similarly for type II 4CL, which also have differences in substrate preference and eventually causes branching in flavonoid biosynthetic pathway [78]. Hence it could be suggested that the remaining non-regulated $4 \mathrm{CL}$ in Boesenbergia rotunda might also be involved in lignin formation or possess different substrates preference.

Chalcone synthase (CHS) is categorized under the type III polyketide synthases superfamily [40]. It catalyzes the formation of chalcones by condensing one p-coumaroylCoA and three malonyl-CoA [80]. Different combination of thioesters and three malonyl-CoA were catalysed by CHS and eventually produce different chalcones for instance, a condensation reaction of p-coumaroyl-CoA gives rise to naringenin chalcone while condensation of cinnamoyl-CoA gives rise to pinocembrin chalcone [40]. It was reported that each CHS has a different substrate preference by in vitro determining CHS relative activity percentage [81]. Although more than one CHS gene was isolated from one species, some CHS isoenzymes were constitutively expressed throughout the plant development with varying expression levels but some were expressed upon induction by environmental stresses including wounding, UV light and pathogen infections [82]. In the transcriptome data, it was showed that one out of 25 CHS mapped in the KEGG database, Unigene1735_All, was up-regulated and seven other unigenes were down-regulated. Thus, it could speculate that Unigene1735_All is a key enzyme that directs the production of panduratin A. Comparison of Unigene1735_All with other CHS in the NR database, the homology search results showed that Unigene1735_All was highly similar to 3-ketoacyl synthase with $53-57 \%$ similarity. Functional studies of Unigene1735_All could be carried out to determine the substrate specificity and their derivative products.

From the findings, it was showed that some of the unigenes that were mapped to PAL, CHS, F3H and ANS were up-regulated. In maize, the $\mathrm{C} 1 \mathrm{MYB}$ transcription factor regulates PAL, CHS, F3H, DFR, ANS and UDPglucose-flavonol glucosyltransferase in the flavonoid pathway [54]. In the results, one MYB transcription factor was up-regulated (Table 4) and correlated with the results of up-regulated unigenes with the exception of DFR. Hence it is possible that the up-regulated MYB in the Boesembergia rotunda transcriptome data is the key regulator for up-regulating this set of unigenes, with the exception of DFR, in the flavonoid pathway. It is suggested that MYB could be a potential target for strategies to overproduce panduratin $\mathrm{A}$ in Boesenbergia rotunda.

Gene regulation patterns in the flavonoid pathway (Table 10) shows that the expression levels of unigenes for anthocyanin production such as F3H, FLS and ANS were higher compared to chalcone production at 1.8 3.8 fold higher in phenylalanine-treated samples than the control. In contrast, higher fold down-regulation was observed for chalcone production which includes PAL, $4 \mathrm{CL}$ and CHS showing a range $1.8-3.3$ fold lower compared to the control. Therefore, it could be inferred that exogenous phenylalanine induction causes a metabolic pathway shift towards higher anthocyanin production, and indirectly increases panduratin A production. Unigenes that may be indirectly involved in the panduratin A biosynthetic pathway are shown in Table 10. Genes directly involved remain to be elucidated until a reference pathway is available. Nevertheless, the unknown unigenes may be involved and this merits further studies such as complementary experiment approach and gene overexpression studies as strategies to understand the unknown pathway.

\section{Conclusion}

This is the first report of Boesenbergia rotunda transcriptome data to elucidate gene regulation pathways in response to exogenous phenylalanine treatment. Through RNA-Seq and differentially expressed genes (DEGs) analysis, gene regulation patterns in the panduratin A biosynthetic pathway was analysed in particular with respect to the flavonoid pathway. Although enzymes that are directly involved in panduratin A production through chalcone remains to be elucidated, other unigenes appear as promising targets for strategies of overproduction of panduratin A in Boesenbergia rotunda through a metabolic engineering strategy. The transcriptome data will also enrich the plant database as a reference for other Zingiberceae family members. 


\section{Methods}

Plant material

The cell suspension cultures were initiated from meristems of the yellow rhizome variety of Boesenbergia rotunda obtained through the Plant Biotechnology Research Laboratory, University of Malaya and were from plants grown under natural conditions. The suspension cultures were propagated in Murashige and Skoog (MS) liquid media [83] supplemented with $1 \mathrm{mg} / \mathrm{l}$ of 6benzylaminopurine (BAP), $1 \mathrm{mg} / \mathrm{l}$ of napthtalene acetic acid (NAA), $1 \mathrm{mg} / \mathrm{l}$ of biotin, $2 \mathrm{mg} / \mathrm{L}$ of 2,4-dichlorophenoxyacetic acid and $99.42 \mathrm{mg} / \mathrm{l}$ of L-glutamine and cultured according to the method described in Tan et. al. 2012 [35]. The cultures were propagated in $250 \mathrm{ml}$ conical flasks shaken at 70-80 rpm using an orbital shaker at $25 \pm 2^{\circ} \mathrm{C}$ under a $16 \mathrm{~h}$ photoperiod with a light intensity of $31.4 \mu \mathrm{mol} / \mathrm{m}^{2} / \mathrm{s}$ provided by cool fluorescent lamp in the growth room.

Equal amounts of the cell suspension $(5 \mathrm{ml}$ of settled cell volume) were used in all experiments. For the control, no phenylalanine was added, while for phenylalanine-treated samples, $40 \mathrm{mg} / \mathrm{l}$ of phenylalanine was added into the propagation media at the beginning of the experiment.

\section{Total RNA extraction}

Phenylalanine-treated cell cultures were harvested after 14 days of propagation. The liquid media was removed and the samples were deep frozen in liquid nitrogen. A modified cetylmethylammonium bromide (CTAB) method was employed to extract total RNA from both control and phenylalanine-treated cell suspension cultures [37]. Initially, 300 to 500 milligram of cell suspension culture was ground in liquid nitrogen. Subsequently the ground sample was added into $2 \mathrm{ml}$ microcentrifuge tubes containing $1 \mathrm{ml}$ of pre-heated CTAB extraction buffer with $20 \mu \mathrm{l} \beta$ mercaptoethanol. Then, the tube was heated at $65^{\circ} \mathrm{C}$ for 10 minutes. The mixture was vortexed for few seconds to mix it well. An equal volume of chloroform:isoamyl alcohol $(24: 1 ; \mathrm{v} / \mathrm{v})$ was then added to the mixture and the mixture vortexed for few seconds.

The mixture of DNA and lysed debris cells was centrifuged in an Eppendorf 5417R centrifuge (Eppendorf, Hamburg, Germany) at $10621 \mathrm{X}$ g for 15 minutes to remove protein impurities. The supernatant was recovered and transferred into a new microcentrifuge tube and the steps repeated 2-3 times. Next, 0.1 volumes of $3 \mathrm{M}$ sodium acetate together with 3 volumes of pre-cooled absolute ethanol were added to the supernatant. The mixture was kept at $-80^{\circ} \mathrm{C}$ for $2-3$ days to precipitate RNA and then centrifuged at $10621 \mathrm{X}$ g for 30 minutes at $4^{\circ} \mathrm{C}$. The supernatant was discarded and the remaining pellet washed with $1 \mathrm{ml}$ of cold $70 \%(\mathrm{v} / \mathrm{v})$ ethanol. The sample was again centrifuged at $10621 \mathrm{X}$ g for 5 minutes at $4^{\circ} \mathrm{C}$, removed and pellet was air-dried and dissolved in $20 \mu \mathrm{l}$ DEPC-treated water.

\section{Library preparation and sequencing}

The quality and quantity of RNA samples were analysed using an Agilent 2100 Bioanalyzer (Agilent, Waldbronn, Germany) to ensure RNA concentrations of more than $400 \mathrm{ng} / \mu \mathrm{l}$ and to obtain RNA quality with an OD 260/ 280 of between $1.8-2.2,28 \mathrm{~S} / 18 \mathrm{~S}>1.8$ and an RNA integrity number $(\mathrm{RIN}) \geq 8$. Whole transcriptome sequencing was carried out using an Illumina-Solexa (Illumina Inc, San Diego, CA, USA) platform at Beijing Genome Institute (BGI), Shenzhen, China.

The Illumina-Solexa platform sequences short fragments of genomic RNA by employing sequence-by synthesis technology. Total RNA samples are sheared by nebulization to yield short fragments approximately between 200-700 bp. Then, cDNA fragments were synthesized by priming these short RNA fragments using random hexamer. Subsequently, two different adaptors were ligated at both ends of the fragments. Single stranded cDNA fragments were then randomly bound on the inside surface of the flow cell channels. Next, the fragments are amplified by solid-phase bridge amplification method. After several PCR cycles, several million dense clusters of double stranded DNA are generated in each channel of the flow cells. Finally, high-throughput sequencing was performed using Illumina-Solexa sequence analyser.

\section{Transcript assembly and annotation}

Sequence data generated from the Illumina-Solexa sequencer was transformed by base calling into sequence data, called raw data or raw reads. The raw data generated from Solexa was filtered by removing the 3' adaptor. Then, the clean data were assembled into transcript contigs by short reads assembling program SOAPdenovo software [84]. This software adopts de the Bruijn graph data sequence data structure to construct contigs. The read were mapped back to the contigs and using the paired-end relationship between reads, contigs from the same transcript can be detected. Next, scaffolds were made by connecting the contigs using SOAPdenovo, in which $\mathrm{N}$ represents the unknown sequence between each two contigs. Paired-end reads were used again to fill the intra-scaffold gaps to form unigenes. As two samples, which were treated and control from the sample species were sequenced, unigenes from each sample's assembly were further assembled to acquire longer nonredundant unigenes using TGI clustering tools [85].

Longer unigenes that were generated by combining both transcripts from control and treated samples were annotated against protein databases such as NR, Swiss-Prot, KEGG and COG by Blastx (e-value cutoff of $<0.00001$ ) 
alignment. The best aligned results were used to determine the sequence direction of the unigenes. Next, for other unaligned unigenes, sequence orientation as well as its coding regions was predicted by using ESTscan software [39].

\section{Unigene functional annotation and expression level}

Functional annotation was done to show the unigenes' protein functional information, which includes protein orthologous groups and pathway annotation. All unigenes with sequence orientation was subjected to functional annotation. Homology search was done by Blastx alignment of unigenes against public protein databases such as NR, Swiss-Prot, KEGG (Kyoto Encyclopedia of Genes and Genomes) and COG (Clusters of Orthologous Groups) with e-value $<0.00001$. Next, in order to classify unigenes in Gene Ontologous (GO) functional annotation, unigenes with $\mathrm{NR}$ annotation information was mapped to their respective ontologies using Blast2GO program [86] and further gene classification was done using WEGO software [87]. Unigenes were classified under three GO-terms namely molecular function, cellular component and biological process. The level of transcripts or unigenes was determined using Reads per kb per Million reads (RPKM) method [88].

\section{Digital Gene Expression analysis for elucidating differentially expressed genes (DEGs)}

In order to identify genes that have different expression levels between control and phenylalanine-treated samples, analysis of differentially expressed genes (DEGs) was done by employing Poisson distribution calculations [89].

\section{Identification and classification of transcription factors and transcription regulators}

Transcription factors (TFs) and transcription regulators (TRs) in Boesenbergia rotunda was identified and classified using iTAK software. iTAK is a program to identify and classify plant transcription factors (TFs) and transcription regulators (TRs) from protein or nucleotide sequences based on the rules (required and forbidden protein domains of each gene family) described in [90]. Protein sequences that were translated from nucleotide sequences generated from the Illumina sequencer were used to find both transcription factors and transcription regulators. ITAK searches both TFs and TRs based on homology search using TFs and TRs from rice database. Subsequently, the differentially regulated TFs and TRs in response to phenylalanine were also identified.

\section{KEGG pathway enrichment analysis}

Different genes usually cooperate with each other to exercise their biological functions. Pathway-based analysis helps to further understand genes biological functions.
Kyoto Encyclopedia of Genes and Genomes (KEGG) is the major public pathway-related database. Pathway enrichment analysis identifies significantly enriched metabolic pathways or signal transduction pathways in DEGs comparing with the whole genome background.

\section{Validation and expression pattern analysis}

To experimentally validate the transcriptional abundance results from sequencing and computational analysis, 9 unigenes were selected for qPCR analysis. The unigenes include 4 random up-regulated unigenes (Unigene58054 All, Unigene57613_All, Unigene555838_All and Unigene54651_All) and 5 unigenes that are annotated in the flavonoid pathway (Unigene10327_All; PAL, Unigene 67845_All; C4H, Unigene41852_All; 4CL, Unigene1735_ All; CHS and Unigene49558_All; F3H). Primers that were used for the experimental validation are shown in Additional file 7. The dissociation curves for all target unigenes are shown in Additional file 8. Reverse transcription reactions were performed using TransScript ${ }^{\circ}$ II Reverse Transcriptase (TransgenBiotech, Beijing, China) with approximately $2 \mu \mathrm{g}$ total RNA following the manufacturer's instructions. Primers for qPCR were designed using Primer 3 software. Elongation factor was used as the reference gene. qPCR was performed on QuantStudio $12 \mathrm{~K}$ Flex realtime PCR platform (Applied Biosystem, Carlsbad, CA, USA) using Power SYBR ${ }^{\circledR}$ Green Master Mix (Applied Biosystem, Carlsbad, CA, USA) to detect transcript abundance. The amplification was achieved by the following PCR protocol: first denaturation at $95^{\circ} \mathrm{C}$ for 10 minutes, then 40 cycles of denaturation at $95^{\circ} \mathrm{C}$ for $15 \mathrm{~s}$, annealing and extension at $60^{\circ} \mathrm{C}$ for 1 minute. The dissociation curve was established at the end of PCR cycle at $95^{\circ} \mathrm{C}$ for $15 \mathrm{~s}, 60^{\circ} \mathrm{C}$ for 1 minute followed by $95^{\circ} \mathrm{C}$ for $15 \mathrm{~s}$. The relative expression levels of the selected unigenes normalized to elongation factor was calculated using $2^{-\Delta \Delta C t}$ method. All reactions were performed with four experimental replicates and data were analyzed using QuantStudio $12 \mathrm{~K}$ Flex software.

\section{Availability of supporting data}

The RNA-seq data supporting the results of this article are available at the NCBI under BioProject with accession number PRJNA256116 with SRA Study accession number SRR1524841 for control untreated and SRR1524842 for phenylalanine treated samples.

\section{Additional files}

Additional file 1: The length distribution of control unigene, phenylalanine treated unigene and All Unigene. All Unigene is a long sequence unigene that is derived from combining both control and phenylalanine treated unigene. 
Additional file 2: The gap distribution of control unigene, phenylalanine treated unigene and All Unigene. All Unigene is a long sequence unigene that is derived from combining both control and phenylalanine treated unigene.

Additional file 3: This table summarizes the number of unigenes that have been assigned in COG functional categories.

Additional file 4: Unigene that are assigned to GO-terms which is classified under biological process, cellular components and molecular function.

Additional file 5: KEGG phenylpropanoid pathway containing gene expression patterns. Red borders represent enzyme that consist of up-regulated unigenes while green borders represent enzyme consist of down-regulated unigenes. Both up- and down-regulated unigenes that mapped to the same enzyme were marked as both red and green borders.

\section{Additional file 6: KEGG flavonoid pathway containing gene} expression patterns. Red borders represent enzymes that consist of up-regulated unigenes while green borders represent enzymes consisting of down-regulated unigenes. Both up- and down-regulated unigenes that mapped to the same enzyme were marked as both red and green borders.

\section{Additional file 7: Primers used for experimental validation.}

Additional file 8: Dissociation curves of target unigenes in qPCR.

\section{Abbreviations}

NR: non-redundant; KEGG: Kyoto Encyclopedia of Genes and Genomes; COG: Cluster Orthologous Group (COG); PAL: phenylalanine ammonia-lyase; C4H: cinnamic-4-hydroxylase; 4CL: 4-coumaroyl:coenzyme A ligase; CHS: chalcone synthase; $\mathrm{CHI}$ : chalcone isomerase; FS1/FS2: flavone synthase 1 and 2; IFS: isoflavone synthase; DFR: dihydroflavonol 4-reductase; F3H: flavanone-3-hydroxylase; FLS: flavonol synthase; ANS: anthocyanidin synthase; LAR: leucoanthocyanidin reductase; ANR: anthocyanidin reductase; MS: Murashige and Skoog; BAP: 6-benzylaminopurine; NAA: napthtalene acetic acid; CTAB: cetyltrimethylammonium bromide; MGI: Malaysia Genome Institute; BGI: Beijing Genome Institute; RIN: RNA integrity number; PCR: polymerase chain reaction; CDNA: complementary deoxyribonucleic acid; DNA: deoxyribonucleic acid; RNA: ribonucleic acid; SOAP: Short Oligonucleotide Analysis Package; RPKM: Reads per kb per Million reads; TFs: Transcription factors; TRs: Transcription regulators; DEGs: Differentially expressed genes; FDR: False Discovery Rate; DGE: Digital gene expression.

\section{Competing interests}

The authors declare that they have no competing interest.

\section{Authors' contributions}

NDMM was involved in all the experiments including preparation of the cell culture for phenylalanine treatment induced callus, extracting the RNA and analysis of the transcriptome profiles between control and treated samples, and drafting of the manuscript. WSM participated in initiating the Boesenbergia rotunda callus and preparing the initial source of cell suspension culture. HG and ZP were involved in library construction, transcriptome sequencing, transcriptome assembly and general analysis. NB and MFA participated in assigning the transcriptome data to iTAK software. YMY participated in the design and coordination of the project. NZK, JAH and RYO initiated the project, conceived the study, and led in the design, supervision and coordination of the study, and drafting of the manuscript. All authors were involved in proofreading the manuscript. All authors read and approved the final manuscript.

\section{Acknowledgements}

This work was supported by grant (07-05-16-MGI-GMB001 grant and 09-05MGI-GMB005) financed by the Ministry of Science, Technology and Innovative (MOSTI) of Malaysia and the University of Malaya (grant FL002-2010 and RP003-2012D) University Malaya High Impact Research Grant (UM.S/P/628/ 3/HIR-MOHE-SC19) in collaboration with Beijing Genome Institute (BGI), Shenzhen, China. We would also like to thank the Malaysia Genome Institute (MGI) for use of their facilities. NDMM was supported by A National Science
Fellowship from the Ministry of Science, Technology and Innovation (MOSTI) of Malaysia.

\section{Author details}

${ }^{1}$ Centre for Research in Biotechnology for Agriculture (CEBAR), University of Malaya, 50603 Kuala Lumpur, Malaysia. ${ }^{2}$ Institute of Biological Sciences, Faculty of Science, University of Malaya, 50603 Kuala Lumpur, Malaysia. ${ }^{3}$ Centre for Foundation Studies in Science, University of Malaya, 50603 Kuala Lumpur, Malaysia. ${ }^{4}$ Centre of Research for Computational Sciences \& Informatics in Biology, Bioindustry, Environment, Agriculture \& Healthcare (CRYSTAL), University of Malaya, 50603 Kuala Lumpur, Malaysia.

${ }^{5}$ BGI-Guangzhou, No.280, Waihuan East Road, Guangzhou Higher Education Mega Center, Guangzhou, China. ${ }^{6}$ BGl-Shenzhen, Shenzhen, China.

Received: 22 July 2013 Accepted: 26 September 2014 Published: 18 November 2014

\section{References}

1. Perry LM, Metzger J: Medicinal Plants of East and Southeast Asia: Attributed Properties and Uses. Cambridge, MA: MIT Press; 1980.

2. Larsen K: Preliminary checklist of the Zingiberaceae of Thailand. Thai Forest Bull (Bot) 1996, 24:35-49.

3. Burkill IH, Birtwistle W, Foxworthy FW, Scrivenor JB, Watson JG: A dictionary of the Economic Products of the Malay Peninsula, Volume 1. Kuala Lumpur, Malaysia: Published on behalf of the governments of Malaysia and Singapore by the Ministry of Agriculture and cooperatives; 1966.

4. Saralamp P, Chuakul W, Temsiririrkkul R, Clayton T: Medicinal Plants in Thailand, Volume 1. Bangkok, Thailand: Department of Pharmaceutical Botany, Faculty of Pharmacy, Mahidol University; 1996.

5. Ching AYL, Tang SW, Sukari MA, Lian GEC, Rahmani M, Khalid K: Characterization of flavonoid derivatives from Boesenbergia rotunda (L.). Malays J Ann Sci 2007, 11(1):154-159.

6. Wijayakusuma HMH: Tumbuhan Berkhasiat Obat Indonesia: Rempah, Rimpang Dan Umbi. Jakarta, Indonesia: Milenia Populer; 2001.

7. Jaipetch $T$, Kanghae $S$, Pancharoen O, Patrick V, Reutrakul V, Tuntiwachwuttikul P, White A: Constituents of Boesenbergia pandurata (syn. Kaempferia pandurata): isolation, crystal structure and synthesis of ( \pm )-Boesenbergin A. Aust J Chem 1982, 35(2):351-361.

8. Mongkolsuk S, Dean FM: Pinostrobin and alpinetin from Kaempferia pandurata. J Chem Soc 1964, 4654-4655.

9. Morikawa T, Funakoshi K, Ninomiya K, Yasuda D, Miyagawa K, Matsuda $H_{\text {, }}$ Yoshikawa M: Medicinal foodstuffs. XXXIV. Structures of new prenylchalcones and prenylflavanones with TNF-alpha and aminopeptidase N inhibitory activities from Boesenbergia rotunda. Chem Pharm Bull 2008, 56(7):956-962

10. Trakoontivakorn G, Nakahara K, Shinmoto H, Takenaka M, Onishi-Kameyama M, Ono H, Yoshida M, Nagata T, Tsushida T: Structural analysis of a novel antimutagenic compound, 4-hydroxypanduratin $\mathrm{A}$, and the antimutagenic activity of flavonoids in a Thai spice, fingerroot (Boesenbergia pandurata Schult.) against mutagenic heterocyclic amines. J Agric Food Chem 2001, 49(6):3046-3050.

11. Tuntiwachwuttikul $P$, Pancharoen $O$, Reutrakul $V$, Byrne $L:\left(1^{\prime} R S, 2^{\prime} S R, 6^{\prime} R S\right)$ (2,6-Dihydroxy-4-methoxyphenyl)-[3'-methyl-2'-(3"-methylbut-2"-enyl)-6'phenyl-cyclohex-3'-enyl] methanone (panduratin A)-a constituent of the red rhizomers of a variety of Boesenbergia pandurata. Aust J Chem 1984, 37(2):449-453.

12. Hwang JK, Chung JY, Baek NI, Park JH: Isopanduratin A from Kaempferia pandurata as an active antibacterial agent against cariogenic Streptococcus mutans. Int J Antimicrob Agents 2004, 23(4):377-381.

13. Kiat TS, Pippen R, Yusof R, Ibrahim H, Khalid N, Rahman NA: Inhibitory activity of cyclohexenyl chalcone derivatives and flavonoids of fingerroot, Boesenbergia rotunda (L.), towards dengue-2 virus NS3 protease. Bioorg Med Chem Lett 2006, 16(12):3337-3340.

14. Yun JM, Kwon H, Mukhtar H, Hwang JK: Induction of apoptosis by panduratin $\mathrm{A}$ isolated from Kaempferia pandurata in human colon cancer HT-29 cells. Planta Med 2005, 71(6):501-507.

15. Yun JM, Kweon MH, Kwon $\mathrm{H}$, Hwang JK, Mukhtar $\mathrm{H}$ : Induction of apoptosis and cell cycle arrest by a chalcone panduratin $\mathrm{A}$ isolated from Kaempferia pandurata in androgen-independent human prostate cancer cells PC3 and DU145. Carcinogenesis 2006, 27(7):1454-1464. 
16. Kirana $\mathrm{C}$, Jones GP, Record IR, McIntosh GH: Anticancer properties of panduratin $A$ isolated from Boesenbergia pandurata (Zingiberaceae). J Nat Med 2007, 61(2):131-137.

17. Win NN, Awale S, Esumi H, Tezuka Y, Kadota S: Bioactive secondary metabolites from Boesenbergia pandurata of Myanmar and their preferential cytotoxicity against human pancreatic cancer PANC-1 cell line in nutrient-deprived medium. J Nat Prod 2007, 70(10):1582-1587.

18. Cheah S-C, Appleton DR, Lee S-T, Lam M-L, Hadi AHA, Mustafa MR: Panduratin A inhibits the growth of A549 cells through induction of apoptosis and inhibition of NF-KappaB translocation. Molecules 2011, 16(3):2583-2598

19. Yanti $\mathrm{OHI}$, Anggakusuma, Hwang JK: Effects of panduratin A isolated from Kaempferia pandurata Roxb. on the expression of matrix metalloproteinase9 by Porphyromonas gingivalis supernatant-induced KB cells. Biol Pharm Bull 2009, 32(1):110-115.

20. Yanti A, Gwon SH, Hwang JK: Kaempferia pandurata Roxb. inhibits Porphyromonas gingivalis supernatant-induced matrix metalloproteinase- 9 expression via signal transduction in human oral epidermoid cells. J Ethnopharmacol 2009, 123(2):315-324.

21. Tewtrakul S, Subhadhirasakul S, Karalai C, Ponglimanont C, Cheenpracha S: Anti-inflammatory effects of compounds from Kaempferia parviflora and Boesenbergia pandurata. Food Chem 2009, 115(2):534-538.

22. Yun JM, Kwon $\mathrm{H}$, Hwang JK: In vitro anti-inflammatory activity of panduratin A isolated from Kaempferia pandurata in RAW264. 7 cells. Planta Med 2003, 69(12):1102-1108.

23. Tuchinda P, Reutrakul V, Claeson P, Pongprayoon U, Sematong T, Santisuk T, Taylor WC: Anti-inflammatory cyclohexenyl chalcone derivatives in Boesenbergia pandurata. Phytochemistry 2002, 59(2):169-173.

24. Cheenpracha S, Karalai C, Ponglimanont C, Subhadhirasakul S, Tewtrakul S: Anti-HIV-1 protease activity of compounds from Boesenbergia pandurata. Bioorg Med Chem 2006, 14(6):1710-1714.

25. Yanti, Rukayadi Y, Lee $\mathrm{KH}$, Hwang JK: Activity of panduratin A isolated from Kaempferia pandurata Roxb. against multi-species oral biofilms in vitro. J Oral Sci 2009, 51(1):87-95.

26. Rukayadi Y, Lee $K$, Han S, Yong D, Hwang JK: In vitro activities of panduratin A against clinical Staphylococcus strains. Antimicrob Agents Chemother 2009, 53(10):4529-4532.

27. Shim JS, Kwon YY, Han YS, Hwang JK: Inhibitory effect of panduratin A on UV-induced activation of mitogen-activated protein kinases (MAPKs) in dermal fibroblast cells. Planta Med 2008, 74(12):1446-1450.

28. Shim JS, Kwon YY, Hwang JK: The effects of panduratin A isolated from Kaempferia pandurata on the expression of matrix metalloproteinase-1 and type-1 procollagen in human skin fibroblasts. Planta Med 2008, 74(3):239.

29. Sohn $J H$, Han $K L$, Lee $S H$, Hwang JK: Protective effects of panduratin A against oxidative damage of tert-butylhydroperoxide in human HepG2 cells. Biol Pharm Bull 2005, 28(6):1083-1086.

30. Shindo K, Kato M, Kinoshita A, Kobayashi A, Koike Y: Analysis of antioxidant activities contained in the Boesenbergia pandurata Schult. rhizome. Biosci Biotechnol Biochem 2006, 70(9):2281-2284.

31. Kim D-Y, Kim M-S, Sa B-K, Kim M-B, Hwang J-K: Boesenbergia pandurata attenuates diet-induced obesity by activating AMP-activated protein kinase and regulating lipid metabolism. Int J Mol Sci 2012, 13(1):994-1005.

32. WHO: Dengue and Severe Dengue. Factsheet No 11. Geneva, Switzwerland: World Health Organization (WHO); 2014.

33. WHO: Dengue Vaccine Research. Geneva, Switzwerland: World Health Organization (WHO); 2014.

34. Chee CF, Abdullah I, Buckle MJC, Rahman NA: An efficient synthesis of $( \pm)$-panduratin $A$ and $( \pm$ )-isopanduratin $A$, inhibitors of dengue-2 viral activity. Tetrahedron Lett 2010, 51(3):495-498.

35. Tan EC, Karsani SA, Foo GT, Wong SM, Abdul Rahman N, Khalid N, Othman S, Yusof R: Proteomic analysis of cell suspension cultures of Boesenbergia rotunda induced by phenylalanine: identification of proteins involved in flavonoid and phenylpropanoid biosynthesis pathways. Plant Cell Tiss Org 2012, 111(2):219-229.

36. Herrmann KM, Weaver LM: The shikimate pathway. Annu Rev Plant Biol 1999, 50(1):473-503.

37. Al-Obaidi JR, Mohd-Yusuf Y, Chin-Chong T, Mhd-Noh N, Othman RY: Identification of a partial oil palm polygalacturonase-inhibiting protein (EgPGIP) gene and its expression during basal stem rot infection caused by Ganoderma boninense. Afr J Biotechnol 2010, 9(46):7788-7797.
38. Li R, Yu C, Li Y, Lam TW, Yiu SM, Kristiansen K, Wang J: SOAP2: an improved ultrafast tool for short read alignment. Bioinformatics 2009, 25(15):1966-1967.

39. Iseli C, Jongeneel CV, Bucher P: ESTScan: a program for detecting, evaluating, and reconstructing potential coding regions in EST sequences. Proc Int Conf Intell Syst Mol Biol 1999, 1999:138-148.

40. Austin MB, Noel JP: The chalcone synthase superfamily of type III polyketide synthases. Nat Prod Rep 2003, 20(1):79-110.

41. Molina C, Zaman-Allah M, Khan F, Fatnassi N, Horres R, Rotter B, Steinhauer $D$, Amenc L, Drevon JJ, Winter P: The salt-responsive transcriptome of chickpea roots and nodules via deepSuperSAGE. BMC Plant Biol 2011, 11(1):31.

42. Sun C, Li Y, Wu Q, Luo H, Sun Y, Song J, Lui EMK, Chen S: De novo sequencing and analysis of the American ginseng root transcriptome using a GS FLX Titanium platform to discover putative genes involved in ginsenoside biosynthesis. BMC Genomics 2010, 11(1):262.

43. Luo H, Sun C, Sun Y, Wu Q, Li Y, Song J, Niu Y, Cheng X, Xu H, Li C: Analysis of the transcriptome of Panax notoginseng root uncovers putative triterpene saponin-biosynthetic genes and genetic markers. BMC Genomics 2011, 12(Suppl 5):S5.

44. Sun Y, Luo H, Li Y, Sun C, Song J, Niu Y, Zhu Y, Dong L, Lv A, Tramontano E: Pyrosequencing of the Camptotheca acuminata transcriptome reveals putative genes involved in camptothecin biosynthesis and transport. BMC Genomics 2011, 12(1):533.

45. Tang Q, Ma X, Mo C, Wilson IW, Song C, Zhao H, Yang Y, Fu W, Qiu D: An efficient approach to finding Siraitia grosvenorii triterpene biosynthetic genes by RNA-seq and digital gene expression analysis. BMC Genomics 2011, 12(1):343.

46. Annadurai RS, Neethiraj R, Jayakumar V, Damodaran AC, Rao SN, Katta MA, Gopinathan S, Sarma SP, Senthilkumar V, Niranjan V: De novo transcriptome assembly (NGS) of Curcuma longa L. rhizome reveals novel transcripts related to anticancer and antimalarial terpenoids. PLoS One 2013, 8(2):e56217.

47. Campbell M, Hahn FM, Poulter CD, Leustek T: Analysis of the isopentenyl diphosphate isomerase gene family from Arabidopsis thaliana. Plant Mol Biol 1998, 36(2):323-328.

48. Avelange-Macherel $\mathrm{M}-\mathrm{H}$, Joyard J: Cloning and functional expression of AtCOQ3, the Arabidopsis homologue of the yeast $\mathrm{COQ} 3$ gene, encoding a methyltransferase from plant mitochondria involved in ubiquinone biosynthesis. Plant J 1998, 14(2):203-213.

49. Bolognese CP, McGraw P: The isolation and characterization in yeast of a gene for arabidopsis S-adenosylmethionine: phospho-ethanolamine N-methyltransferase. Plant Physiol 2000, 410:455-3875.

50. Frémont N, Riefler M, Stolz A, Schmülling T: The Arabidopsis TUMOR PRONE5 Gene Encodes an acetylornithine aminotransferase required for arginine biosynthesis and root meristem maintenance in blue light. Plant Physiol 2013, 161(3):1127-1140.

51. Zhang X-N, Han Z-H, Yin L-L, Kong J, Xu X-F, Zhang X-Z, Wang Y: Heterologous functional analysis of the Malus xiaojinensis MxIRT1 gene and the His-box motif by expression in yeast. Mol Biol Rep 2013, 40(2):1499-1504.

52. Fett-Neto AG, Melanson SJ, Sakata K, DiCosmo F: Improved growth and taxol yield in developing calli of Taxus cuspidata by medium composition modification. Nat Biotechnol 1993, 11(6):731-734.

53. Fett-Neto AG, Melanson SJ, Nicholson SA, Pennington JJ, DiCosmo F: Improved taxol yield by aromatic carboxylic acid and amino acid feeding to cell cultures of Taxus cuspidata. Biotechnol Bioeng 1994, 44(8):967-971.

54. Vom Endt D, Kijne JW, Memelink J: Transcription factors controlling plant secondary metabolism: what regulates the regulators? Phytochemistry 2002, 61(2):107-114.

55. Broun P: Transcription factors as tools for metabolic engineering in plants. Curr Opin Plant Biol 2004, 7(2):202-209.

56. Du H, Zhang L, Liu L, Tang XF, Yang WJ, Wu YM, Huang YB, Tang YX: Biochemical and molecular characterization of plant MYB transcription factor family. Biochemistry (MosC) 2009, 74(1):1-11.

57. Mizoi J, Shinozaki K, Yamaguchi-Shinozaki K: AP2/ERF family transcription factors in plant abiotic stress responses. Biochim Biophys Acta 2012, 1819(2):86-96.

58. Ülker B, Somssich IE: WRKY transcription factors: from DNA binding towards biological function. Curr Opin Plant Biol 2004, 7(5):491-498.

59. Jakoby M, Weisshaar B, Dröge-Laser W, Vicente-Carbajosa J, Tiedemann J, Kroj T, Parcy F: bZIP transcription factors in Arabidopsis. Trends Plant Sci 2002, 7(3):106-111 
60. Hirsch S, Oldroyd GED: GRAS-domain transcription factors that regulate plant development. Plant Signal Behav 2009, 4(8):698-700.

61. Olsen AN, Ernst HA, Leggio LL, Skriver K: NAC transcription factors: structurally distinct, functionally diverse. Trends Plant Sci 2005, 10(2):79-87.

62. Hiraga S, Sasaki K, Ito H, Ohashi Y, Matsui $\mathrm{H}$ : A large family of class III plant peroxidases. Plant Cell Physiol 2001, 42(5):462-468.

63. Marjamaa K, Kukkola EM, Fagerstedt KV: The role of xylem class III peroxidases in lignification. J Exp Bot 2009, 60(2):367-376.

64. Kim YH, Kim CY, Song WK, Park DS, Kwon SY, Lee HS, Bang JW, Kwak SS: Overexpression of sweetpotato swpa4 peroxidase results in increased hydrogen peroxide production and enhances stress tolerance in tobacco. Planta 2008, 227(4):867-881.

65. Hiraga S, Yamamoto K, Ito H, Sasaki K, Matsui H, Honma M, Nagamura Y, Sasaki T, Ohashi Y: Diverse expression profiles of 21 rice peroxidase genes. FEBS Lett 2000, 471(2):245-250.

66. Lattanzio V, Cardinali A, Ruta C, Fortunato IM, Lattanzio VM, Linsalata V, Cicco N: Relationship of secondary metabolism to growth in oregano (Origanum vulgare L.) shoot cultures under nutritional stress. Environ Exp Bot 2009, 65:54-62.

67. Herms DA, Mattson WJ: The dilemma of plants: to grow or defend. Q Rev Biol 1992, 67:283-335.

68. Lerdau M, Coley PD: Benefits of the carbon-nutrient balance hypothesis. Oikos 2002, 98(3):534-536.

69. Jones CG, Hartley SE: A protein competition model of phenolic allocation. Oikos 1999, 86(1):27-44.

70. Jaipetch T, Reutrakul V, Tuntiwachwuttikul P, Santisuk T: Flavonoids in the black rhizomes of Boesenbergia panduta. Phytochemistry 1983, 22(2):625-626.

71. Herunsalee A, Pancharoen O, Tuntiwachwuttikul P: Further studies of flavonoids of the black rhizomes Boesenbergia pandurata. J Sci Soc Thailand 1987, 13:119-122.

72. Bowsher C, Steer MW, Tobin AK: Plant biochemistry. NY, USA: Garland Science; 2008

73. Lois R, Dietrich A, Hahlbrock K, Schulz W: A phenylalanine ammonia-lyase gene from parsley: structure, regulation and identification of elicitor and light responsive cis-acting elements. EMBO J 1989, 8(6):1641-1648.

74. Wanner LA, Li G, Ware D, Somssich IE, Davis KR: The phenylalanine ammonia-lyase gene family in Arabidopsis thaliana. Plant Mol Biol 1995, 27(2):327-338

75. Fukasawa-Akada T, Kung SD, Watson J: Phenylalanine ammonia-lyase gene structure, expression, and evolution in Nicotiana. Plant Mol Biol 1996, 30(4):711-722.

76. Cramer C, Edwards K, Dron M, Liang X, Dildine S, Bolwell GP, Dixon R, Lamb C, Schuch W: Phenylalanine ammonia-lyase gene organization and structure. Plant Mol Biol 1989, 12(4):367-383.

77. Joos HJ, Hahlbrock K: Phenylalanine ammonia-lyase in potato (Solanum tuberosum L.). Eur J Biochem 2005, 204(2):621-629.

78. Ehlting J, Büttner D, Wang Q, Douglas CJ, Somssich IE, Kombrink E: Three 4-coumarate: coenzyme A ligases in Arabidopsis thaliana represent two evolutionarily divergent classes in angiosperms. Plant J 2002, 19(1):9-20.

79. Gui J, Shen J, Li L: Functional characterization of evolutionarily divergent 4coumarate: Coenzyme A ligases in rice. Plant Physiol 2011, 157(2):574-586.

80. Ferrer $J$, Jez JM, Bowman ME, Dixon RA, Noel JP: Structure of chalcone synthase and the molecular basis of plant polyketide biosynthesis. Nat Struct Biol 1999, 6(8):775.

81. Yamazaki Y, Suh DY, Sitthithaworn W, Ishiguro K, Kobayashi Y, Shibuya M, Ebizuka $Y$, Sankawa U: Diverse chalcone synthase superfamily enzymes from the most primitive vascular plant, Psilotum nudum. Planta 2001, 214(1):75-84.

82. Wingender $\mathrm{R}$, Röhrig $\mathrm{H}$, Höricke $\mathrm{C}$, Wing $\mathrm{D}$, Schell J: Differential regulation of soybean chalcone synthase genes in plant defence, symbiosis and upon environmental stimuli. Mol Gen Genet 1989, 218(2):315-322.

83. Murashige T, Skoog F: A revised medium for rapid growth and bio assays with tobacco tissue cultures. Physiol Plant 1962, 15(3):473-497.

84. Li R, Zhu H, Ruan J, Qian W, Fang X, Shi Z, Li Y, Li S, Shan G, Kristiansen K: De novo assembly of human genomes with massively parallel short read sequencing. Genome Res 2010, 20(2):265-272.

85. Pertea G, Huang X, Liang F, Antonescu V, Sultana R, Karamycheva S, Lee $Y$, White J, Cheung F, Parvizi B: TIGR Gene Indices clustering tools (TGICL): a software system for fast clustering of large EST datasets. Bioinformatics 2003, 19(5):651-652.
86. Conesa A, Götz S, García-Gómez JM, Terol J, Talón M, Robles M: Blast2GO: a universal tool for annotation, visualization and analysis in functional genomics research. Bioinformatics 2005, 21(18):3674-3676.

87. Ye J, Fang L, Zheng H, Zhang Y, Chen J, Zhang Z, Wang J, Li S, Li R, Bolund L: WEGO: a web tool for plotting GO annotations. Nucleic Acids Res 2006, 34(suppl 2):W293-W297.

88. Mortazavi A, Williams BA, McCue K, Schaeffer L, Wold B: Mapping and quantifying mammalian transcriptomes by RNA-Seq. Nat Methods 2008, 5(7):621-628.

89. Audic S, Claverie J-M: The significance of digital gene expression profiles Genome Res 1997, 7(10):986-995.

90. Pérez-Rodríguez P, Riaño-Pachón DM, Corrêa LGG, Rensing SA, Kersten B, Mueller-Roeber B: PInTFDB: updated content and new features of the plant transcription factor database. Nucleic Acids Res 2010, 38(Suppl 1):D822-D827.

doi:10.1186/1471-2164-15-984

Cite this article as: Md-Mustafa et al.: Transcriptome profiling shows gene regulation patterns in a flavonoid pathway in response to exogenous phenylalanine in Boesenbergia rotunda cell culture. BMC Genomics 2014 15:984.

\section{Submit your next manuscript to BioMed Central and take full advantage of:}

- Convenient online submission

- Thorough peer review

- No space constraints or color figure charges

- Immediate publication on acceptance

- Inclusion in PubMed, CAS, Scopus and Google Scholar

- Research which is freely available for redistribution 